\title{
Plasmodium falciparum Serine/Threonine Phoshoprotein Phosphatases (PPP): From Housekeeper to the 'Holy Grail'
}

\author{
Joanna Bajsa ${ }^{1, *}$, Stephen O. Duke ${ }^{1}$ and Babu L. Tekwani ${ }^{2}$ \\ ${ }^{1}$ United States Department of Agriculture-Natural Products Utilization Research Unit, National Center for Natural \\ Products Research, University MS 38677 and ${ }^{2}$ National Center for Natural Products Research and Department of \\ Pharmacology, University of Mississippi, University MS 38677, USA
}

\begin{abstract}
Availability of complete genome sequence for Plasmodium falciparum has been useful in drawing a comprehensive metabolic map of the parasite. Distinct and unique metabolic characteristics of the parasite may be exploited as potential targets for new antimalarial drug discovery research. Reversible phosphorylation of proteins is a ubiquitous process and an indispensable part of cell signaling cascades, which regulate different cellular functions. Not so long ago the role of protein phosphatases in the cell life was underestimated but now these enzymes strongly focus attention of many researches. Based on primary structure and functional characteristics protein phosphatases have been divided into number of families and subfamilies. The amino acid sequences of catalytic subunits of protein phosphatases of particular families stay highly conserved in eukaryotic organisms during evolutionary changes. Serine/threonine protein phosphatases (PPPs) constitute an important family, which are involved in mitotic and meiotic cell divisions, cell development, apoptosis and many other crucial cellular processes. Complex life cycle of the malaria parasite, which encompasses through distinct developmental stages, offers highly sophistical roles for the protein phosphatases. We have researched and analyzed characteristics of 17 putative or/and confirmed catalytic subunits of PPPs on $P$. falciparum genome. Evidences have been gathered that indicate functional expression of some PPP isoforms in P. falciparum. A few of them have been found to be essential or play important cellular functions in the parasite. Identification of distinct molecular and functional characteristics of these enzymes shall be useful in designing selective inhibitors of plasmodial PPPs as potential new antimalarials.
\end{abstract}

Key Words: Plasmodium falciparum, protozoa, serine/threonine protein phosphatase, protein dephosphorylation,

\section{INTRODUCTION}

Malaria kills more than 2 million people every year and almost half of the global population is exposed to the risk of being infected with malaria [1]. Infections with Plasmodium falciparum and the children below 5 years of age, particularly in the sub-Saharan region of Africa, account for almost $90 \%$ of malaria-related deaths. Malaria has had a substantial influence on human history. For example, it has influenced the outcomes of several wars and has drained a number of national economies. Although the high incidences of malaria are mostly centered in tropical regions, the impacts, especially economic, of the disease are global. Recent trends indicate rapid emergence of drug-resistant and more virulent strains of these parasites to further intensify the problem [2]. The choice of therapies currently available for treatment of malaria is highly limited, and several of these may eventually be lost or compromised due to drug resistance. The genome sequencing project of Plasmodium falciparum, the causative agent for almost all malaria related deaths, has paid off in drawing a comprehensive metabolic map of the parasite [3]. The system biology efforts [4] and continued exercise on annotation and reannotation of the parasite genes [5]

*Address correspondence to this author at the United States Department of Agriculture-Natural Products Utilization Research Unit, National Center for Natural Products Research, University MS 38677;

E-mail: jbajsa@olemiss.edu have helped in identification of several pathways and/or the metabolic functions unique to the parasite (http://sites.huji. ac.il/malaria/). Detailed analyses of these distinctly unique pathways, metabolic steps and the enzymes are providing potential targets for new antimalarial drug discovery [6]. Several global efforts have recently been initiated in these directions [7].

The malaria parasite completes its life cycle through several distinct developmental stages, namely rings, trophozoites, schizonts, merozoites, male and female gametocytes in the vertebrate hosts. Each developmental stage is accompanied with selective expression of unique sets of genes generating unique sets of proteomes. Therefore, the enzymes and proteins associated with cell cycle and signal transduction pathways offer highly promising targets for selective interruption of development, growth and proliferation of the malaria parasite. A detailed understanding about these pathways, especially molecular, structural and functional characteristics of the enzymes, shall be useful in design and development of selective enzyme inhibitors as potential new antimalarials. In view of the novelty of these molecular targets, these inhibitors are likely to be effective against the multidrug resistant strains of the parasite.

Protein phosphatases may be an interesting source of antiplasmodial targets, in view of their crucial and unique role in the parasite cell life cycle. The phosphorylation and dephosphorylation reactions of proteins are fundamental 
forms of regulation of enzymatic activities in the cells [8]. This unique process is present in cells of all living creatures on earth. The protein kinases and phosphatases are the main players of this game, which help to keep an overall cellular equilibrium. For many years the role of protein phosphatases (PPs) was underestimated and disregarded. Initially, kinases were more interesting research subjects probably because of the abundance and diversity of the genes encoding these enzymes; the human genome consists of around 500 genes encoding protein kinases [9]. Genomes of different species contain only a few copies of the genes encoding the catalytic subunit of a particular PPP e.g. the Arabidopsis thaliana genome contains nine PP1, five of PP2A, 2 PP4, one PP5, two PP6 and three PP7; Leishmania major contains eight PP1, two of PP2A, one PP4, one PP5, one PP6 and one PP7 $[10,11]$. These seem to be too few for such a complicated system of signal transduction. Therefore, protein-protein interactions appear to be crucial for regulation of activity and creating diversity of protein phosphatases. Protein phosphatase $2 \mathrm{~A}$ assembles as a holoenzyme consisting of catalytic and regulatory subunits. This diversity creates enormous capabilities for modulation of activity of protein phosphatases e.g. human PP could be composed of approximately 72 possible PP holoenzymes [12].

In this review we have primarily focused on characteristics and functions of Plasmodium falciparum serine/threonine protein phosphatases and have also discussed how these enzymes are important for the parasite and might be potential molecular targets for new antimalarial drug discovery. A brief general account of molecular and functional characteristics of PPPs has also been presented, which would help in understanding and analyzing the features of plasmodial PPPs.

\section{PROTEIN PHOSPHATASES FAMILY}

Based on primary structure, enzyme properties and functional characteristic protein phosphatases have been divided into four different families (Fig. 1). High amino acid sequence homology among the protein phosphatases of each group has been conserved across different species [13, 14]. This indicates the importance of these enzymes in regulation of signal transduction functions. Protein serine/threonine phosphatases (PPPs) constitute a large family consisting of two classes: the first group includes subclasses PP1, PP2A, PP2B (calcineurin), PP4, PP5, PP6, PP7 and second group includes PPM $\left(\mathrm{Mg}^{2+}\right.$-dependent protein phosphatase). PP2C and mitochondrial pyruvate dehydrogenase phosphatase are also the members of the PPM family [15] (Fig. 1). Interestingly, the primary structure of PP2C differs from others PPP, but they have significant similarities at the level of three dimensional structure. The PPPs from both of these groups dephosphorylate serine and threonine. The most recently described protein phosphatase family has been identified as protein-histidine phosphatases (PHP), which are involved in histidine phosphorylation signal transduction. There is relatively little information available about this PP family [16] The genes encoding PHPs have been isolated and analyzed in the eukaryotes as well as prokaryotes [17, 18]. Similar to other protein phosphatases, the amino acid sequence of PHP is also conserved in different species [17]. Another protein phosphatase family is constituted of two classes, namely protein tyrosine phosphatases (PTP) and dual function protein phosphatases (DSPs). PTP dephosphorylate tyrosine residues, while DSPs dephosphorylate all three phosphoamino acids (serine, threonine and tyrosine). The dephosphorylation reaction of PTP is based on formation of a covalent phosphocysteine intermediate during catalytic turnover [19]. The dephosphorylation reactions catalyzed by PPP and PTP differ significantly. These PPs are also characterized by their differential sub-cellular localization; PPPs have been mostly found in the cytoplasm, while PTPs are mainly membrane bound proteins [20]. Okadaic acid (OA), a toxin initially isolated from a marine sponge Halichondria okadai, has been identified as a selective inhibitor of PPPs [21]. Differential sensitivities of PPP to OA have helped in further sub-classification of the family of PPP [22]. OA strongly inhibits PP1, 2A, and 2B. The inhibitory effect of okadaic acid is strongest for $2 \mathrm{~A}$, followed by 1 , and then $2 \mathrm{~B}$. The

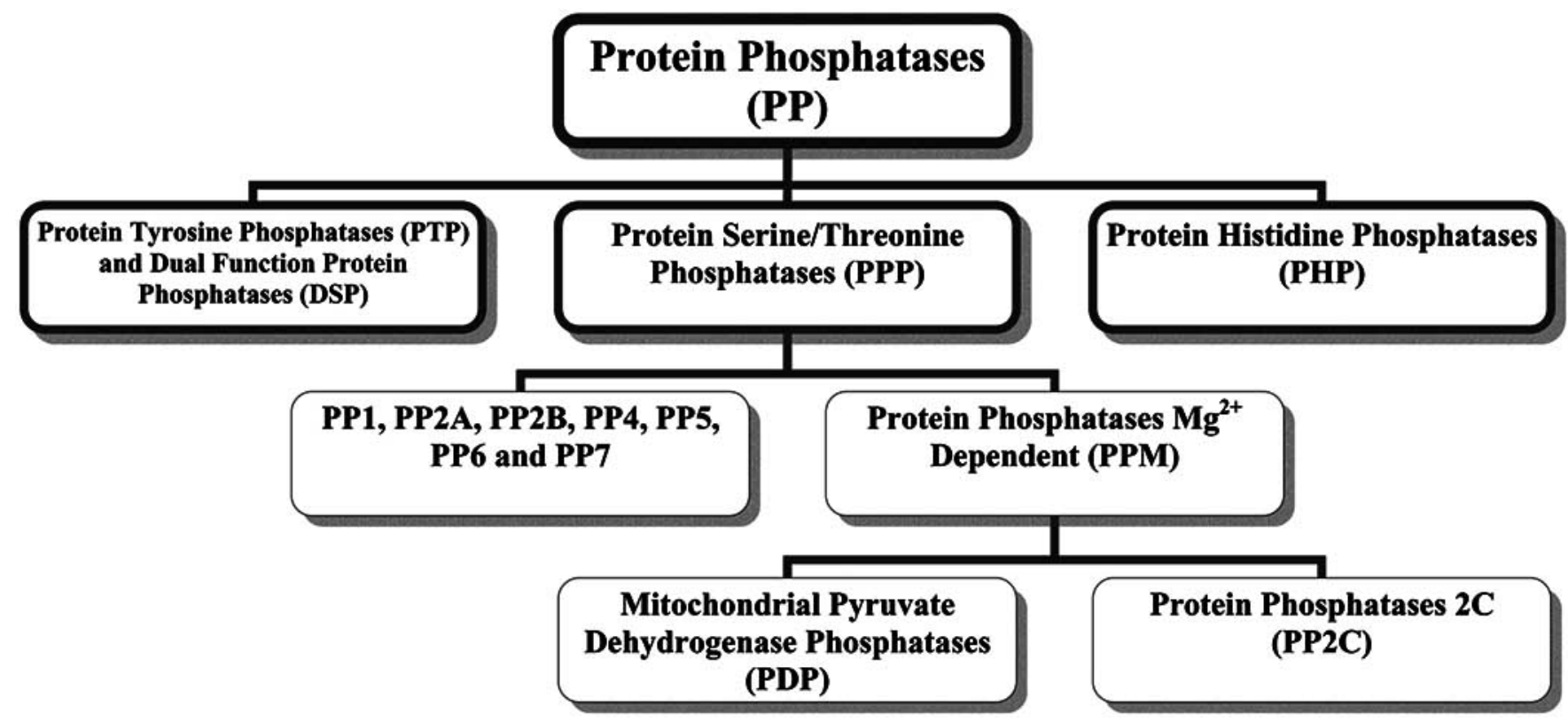

Fig. (1). General classification of protein phosphatases. 
$\mathrm{PP} 2 \mathrm{C}$ is not inhibited by OA. The inhibition of PP1 requires 10-100 times higher concentration of OA than for inhibition of PP2A [20]. The $\beta$-subunit of phosphorylase kinase is dephosphorylated by PP1, but PP2 dephosphorylates the $\alpha$ subunit [22]. Amino acid sequences of PP1 and PP2A have conserved $50 \%$ identity [23], with the domains responsible for catalytic activity maintaining the highest identity. The core of catalytic subunit of PPP plays the main role in catalysis, but $\mathrm{N}$ and $\mathrm{C}$ terminals mainly have regulatory functions namely, binding of subunits and with cations.

\section{PROTEIN SERINE/THREONINE PHOSPHATASE 1 (PP1)}

The amino acid sequence of catalytic subunits of PP1 is highly conserved among different species with as high as 90\% identity Fig. (2) [24]. The catalytic subunit alone, with MW ranging from 35 to $38 \mathrm{kDa}$, has extraordinarily high catalytic activity. To control dephosphorylation, PP1 is assembled as multimeric holoenzymes, which consist of catalytic (C) and regulatory (R) subunits [24]. The regulatory subunit also determines sub-cellular localization of PP1. PP1 is divided into two groups by their evolutionary development, namely primary and secondary. The PP1 from the primary group have apparently always interacted with $\mathrm{C}$ subunits, while PP1 of the secondary group evolved to acquire the ability to interact with the $\mathrm{C}$ subunit. Some of the orthologs in secondary $\mathrm{R}$ sub-group do not have the charac- teristic binding elements a $\mathrm{C}$ subunit. Both these groups consist of many members. There are 45 known regulatory subunits in the human genome [25]. Amino acid sequences of regulatory subunits significantly differ from each other. Their presence can be predicted based on domains or motifs responsible for protein-protein interaction. Depending on the characteristics of $\mathrm{R}$ subunits, they can bind different regions of PP1. These interactions are not limited to one binding site [25]. Recently, determination of tertiary structure of PP1C has identified specific binding sites, like the RVXF binding channel-hydrophobic groove. The binding of the regulatory subunit in RVXF binding site does not cause serious structural changes to modify PP1 enzymatic activity. Probably, this structure acts as a clinch which enables further interaction of regulatory and catalytic subunits. One third of all eukaryotic proteins have the RVXF consensus motif, but not all of them are PP1 regulatory subunits $[25,26]$.

The $\beta 12-\beta 13$ loop is a binding site for the inhibitors, e.g. OA, cantharidin, I1 and I2. This region consists of $\alpha_{4}, \alpha_{5}$ and $\alpha_{6}$ responsible for interaction with $\mathrm{Sds} 22$. This $\mathrm{R}$ subunit of PP1 controls dephosphorylation of Aurora-type kinases substrates [27]. PP1 seems to be a multifunctional enzyme which is deeply engaged in many crucial cellular processes. PP1 are indispensable elements in cell division, translation, transcription, apoptosis and even RNA splicing. PP1 inactivation by mutation, knockout and toxins cause mitotic arrest $[26,28,29]$. In mitosis phase $\mathrm{G}_{2}$, histone $\mathrm{H} 3$ is phosphory-

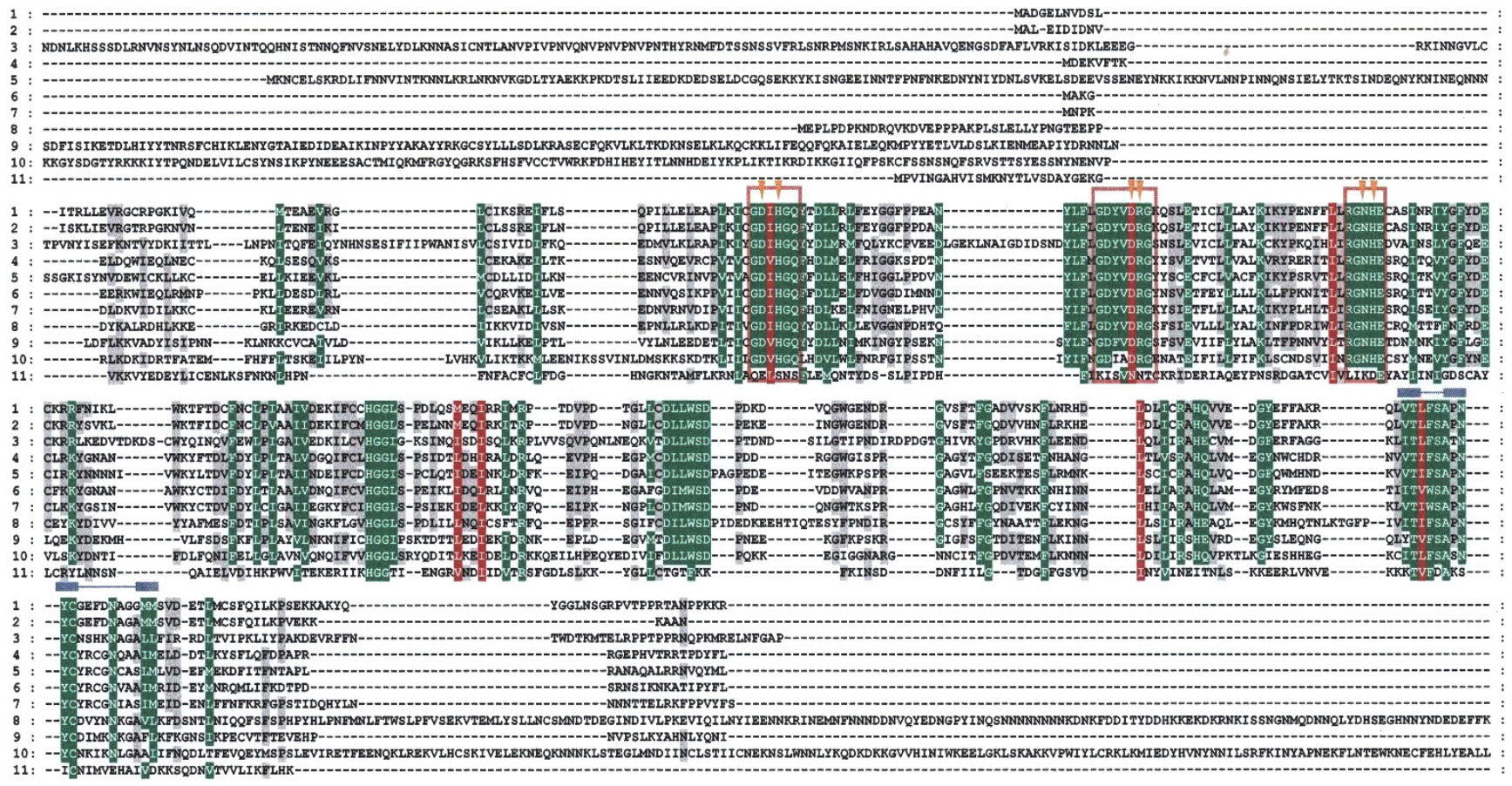

- Amino acid residues forming part of substrate binding and catalytic subunit (D64, H66, D95, R96, N124, H125)

- Characteristic, conservative motifs of catalytic domains of serine/threonine protein phosphatases; GDIHGQ, GDYVDRG, RGNHE (this domain is called a "signature of catalytic domain of PPP") and SAPNYC

$=-$ The loop between $\beta 12$ and $\beta 13$ (contain domain SAPNYC) binding inhibitors e.g. okadaic acid 1. HsPP1 (NM_206876) 2. PfPP1 (PF14_0142/AAN36754) 3. Pf PPa (PF14_0630/AAN37243) 4. HsPP2A (NM_002715) 5. PfPPß (PFI1245c/CAD51935) 6. PfPP2A (PFC0595c/CAB38970) 7. PfPP2A like (PFI1360c /CAD51958) 8. PfPP2B (PF08_0129/CAD51335) 9. Pf PfPP5 (MAL13P1.274/CAD52675) 10. PfPPJ (PF14_0224/AAN36837) 11. PfPP2C-like (MAL8P1.108/ CAD51270) (Table 1 for other details on PfPPP sequences).

Fig. (2). Primary structures and alignment of amino acid sequences of PPPs (core fragment of catalytic subunit) from Plasmodium falciparum and Homo sapiens. 
lated by a protein kinase belonging to Aurora family. Probably, the PP1 is involved in dephosphorylation of H3 during telophase. Presumably, Aurora - B (animals) may even interact directly with PP1. PP1 is also involved in apoptosis by assembling a complex with proteins $\mathrm{Bcl}-2$ and Bad. Bcl-2 protein is located in the membranes of mitochondria, endoplasmic reticulum and nucleus. PP1 dephosphorylates Bcl-2. Disturbances like hyperphosphorylation of $\mathrm{Bcl}-2$ activate apoptosis. The Bad pro-apoptotic proteins in the dephosphorylated stage activate caspases [28]. RNA polymerase II is phosphorylated by cyclin-dependent kinases during transcription. When RNA polymerase II finishes that process it undergoes dephosphorylation reaction by PP1 [26]. Interestingly, many of regulatory subunits belong to the kinase family, and PP1 directly activates or deactivates them.

\section{PROTEIN SERINE/THREONINE PHOSPHATASE 2A (PP2A)}

PP2A referred by some researchers as the 'holy grail' is a heterotrimeric holoenzyme consisting of catalytic subunit (C), regulatory subunit (PR65/A) and B subunit (with regulatory function). A hook-shaped subunit PR65/A interacts with subunits $\mathrm{C}$ and $\mathrm{B}$ by a hydrophobic surface, which is comprised of 15 non-identical leucine rich repeats (HEAT repeats) [30]. In some cases, specific regulatory subunits, for example SV40 small T or polyomavirus small and middle T antigens, interact with a different region of 10 repeats [31]. Vertebrate genomes contain two isoforms of regulatory subunit PR65 $\beta$, PR65A $\alpha$ and two isomeric forms of catalytic subunits [16]. PR65 $\beta$ plays an important role in cancer as a putative human tumor suppressor. Mutations of the gene encoding subunit A $\alpha$ have been found in human carcinomas [32]. The PP2A catalytic subunit is a globular protein which consists of very conservative domains that have remained almost identical among a wide range of species, e.g. plants, yeast and mammals $[32,33]$. The catalytic isoforms do not influence creation of the holoenzyme and also have similar activity. Their amino acid sequences differ by only nine amino acids, which are not responsible for catalysis process [34]. In vitro, PP2A as a monomer $\mathrm{C}$ subunit, shows high catalytic activity and lower specificity. Interaction of $\mathrm{C}$ subunit with other regulatory subunits increases its substrate specificity and decreases the catalytic efficiency. The subunit $\mathrm{C}$ and subunit $\mathrm{A}$ together create a core dimer, which binds to the regulatory subunit $\mathrm{B}$. The enzymatic activity of PP2A is modulated by interaction with the subunit B. Some researchers suggested that activity and substrate affinity of PP2A are strongly regulated by a pool of specific subunit B distributed in different sub-cellular compartments. It is assumed that there are other factors, depending on localization of the PP2A enzyme complex, which can modify specificity of the holoenzyme [30]. The regulatory subunits B, contrary to limited number of catalytic and PR65 subunits, create a large and diverse group of proteins. The sequences of regulatory $\mathrm{B}$ subunits are highly diversified, resulting in large numbers of PP2A holoenzyme variants. This explains the mechanism of regulation of different cellular functions by PPPs. The mammalian regulatory $B$ subunits have been divided into four families: PR55, PR61, PR72 and PR93/PR110 [32]. During last few years the intense research activities in this area have also discovered homologous genes in other species (e.g. Homo sapiens, Arabidopsis thaliana, Saccharomyces cerevisiae, Dictiostelium discoideum, Xenopus). The level of expression of most of the $\mathrm{PP} 2 \mathrm{~A}$ regulatory $\mathrm{B}$ subunit depends on the type of the tissue or cell [35].

\section{REGULATION OF EXPRESSION AND ENZYMATIC FUNCTIONS OF PP2A}

Expression of genes encoding PP2A and enzymatic activity are tightly regulated in a sophisticated manner. There are different mechanisms, which keep expression of PP2A stable. First of all, this enzyme can be toxic to the producing organism. Any uncontrolled changes of expression can be lethal. This explains the failure of numerous attempts to modify expression of PP2A gene by mutation, deletion and overexpression. The regulation of $\mathrm{PP} 2 \mathrm{~A}$ expression starts at the transcription level. The domains and the critical amino acids involved in post-translational modifications of PP2A have also been conserved during evolution. The role of three crucial amino acids Thr304, Tyr307, Leu309 is critical (Fig. 3). First two are phosphorylation sites, which take part in autophosphorylation. Those particular reactions cause inhibition of enzymatic activity. Formation of a PP2A heterotrimer from heterodimer A-C depends on carboxymethylation of Leu309. The PP2A-methyltransferase (PPMT) and methylesterase (PME-1) are responsible for methylation and demethylation of PP2A $[35,36]$. It is still unclear how methylation affects catalytic activity of PP2A. Yoo et al [36] compared the methylation level of a pool of PP2A dimers and trimers from fetal and adult rat liver. Enzymes involved in the process of methylation did not show changes in the fetal liver, however these extracts were comprised of more methylated heterotrimers than adult liver preparations. Adult liver extracts contain unmethylated monomers of PP2A catalytic subunits. This observation is surprising since the monomeric PP2A subunits have been shown to be unstable [32]. Some reports suggest that the methylation level could also depend partly on the cell cycle (differing between G0/G1 and G1/S stages) [36]. However, regulation of activity of PP2A by methylation is still not clear. There are probably other factors besides methylation enzymes and cell cycle which alter affinity of PP2A subunits to each other and substrate specificity. A simple substitution (Leu309/A309) or deletion (Leu309/0) has shown that assembly of the enzyme complex and PP2A activity may not depend on methylation of Leu309 at all [37]. The role of protein-protein interactions in regulation of $\mathrm{PP} 2 \mathrm{~A}$ function has also been suggested. For example, PP2A can respond to signals and move between sub-cellular compartments, where interaction of PP2A with the microtubule cytoskeleton proteins can inactivate certain pools of PP2A [35]. PP2A is indispensable for signal transduction. Therefore, it is crucial for many processes such as transcription, translation, DNA replication, and cell cycle functions. The viral protein SV40 small t-antigen mimics a regulatory subunit B of PP2A heterotrimer [38]. Recently, Rodriguez et al [39] showed that the polyomavirus small tantigen is not involved in MAPK but PI3-kinase signal transduction. In both cases SV40 and polyomaviral subunit substitution in PP2A complex leads to induction of cell proliferation but in an abnormal manner [39]. The role of PP2A function has also been shown in Alzheimer's disease. During Alzheimer's disease, the structures called paired helical 

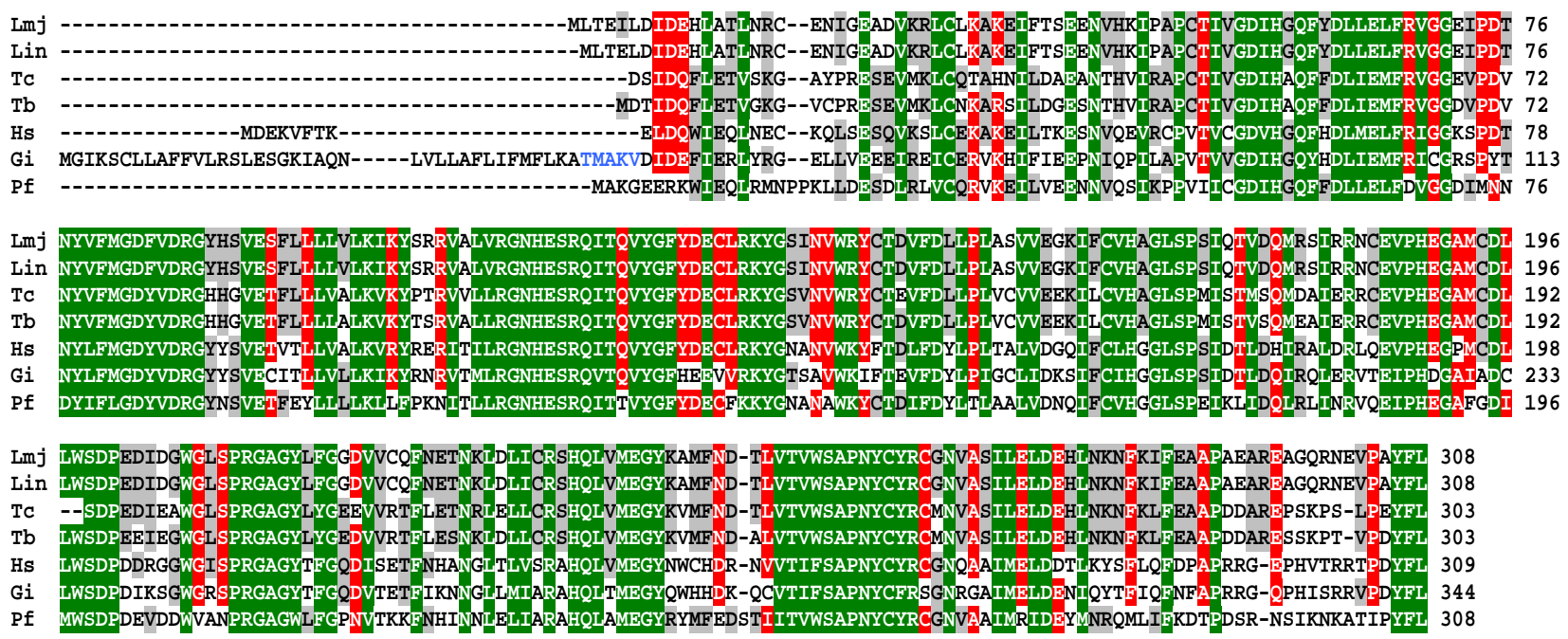

Fig. (3). Alignment of amino acid sequences PP2A from Homo sapiens (Hs) (NM_002715), Plasmodium falciparum (Pf) (PFC0595c/ CAB38970), Leishmania infantum (Lin) (CAM71071), Leishmania major (Lmj) (CAJ08835), Trypanosoma brucei (Tb) (EAN80641), Trypanosoma cruzi (Tc) (EAN89463) and Giardia lamblia (Gi) (EAA37747). TMA-KV - cleavage between 41 and 42 amino acids- putative signal peptide.

filaments (PHF) are formed in brain. PHF are built from the tau protein in a hyperphosphorylated stage [40]. Decreased levels of PP2A may be responsible for this, as tau is associated with microtubules and is dephosphorylated by PP2A [40].

\section{PLASMODIUM FALCIPARUM SERINE/THREONINE PROTEIN PHOSPHATASES (PfPPPS)}

The malaria parasite (Plasmodium spp) has a complex life cycle encompassing through multiple developmental stages and different physiological environments in the hosts. The parasite, therefore, must possess highly precise and complex machinery to regulate these modifications. Protein phosphatases should play a meaningful role in these processes. We have compiled the literature data and information from different database websites related to the Plasmodium falciparum genome (Build 1.1 statistics; http://www.ncbi. nlm.nih.gov/mapview and PlasmoDB; GeneDB) to find the plasmodial genes coding protein phosphatases. We have identified and analyzed phylogeny of 17 putative or/and confirmed PPPs catalytic subunits (Table 1) (Fig. 4). In order to verify PP families of the putative proteins, we used BLAST (http://www.ncbi.nlm.nih.gov/BLAST). Seven of these subunits were classified as protein phosphatases 2C (PFD0505c/ CAB62878, PFE1010w/ CAD51566, MAL8P1.108/ CAD 51270, MAL8P1.109/ CAD51272, PF11_0396/ AAN35979, MAL13P1.44/ CAD52227, PF14_0523/ AAN37136), two were identified as PP1 [PF14_0142/ AAN36754 and PF14_ 0630/ AAN37243- $(\mathrm{PP} \alpha)]$, three were classified as PP2A [PFI1245c/ CAD51935 (PP $\beta$ ), PFC0595c/ CAB38970 and PFI1360c/ CAD51958] and one each were identified as PP2B-calcineurin (PF08_0129/ CAD51335), PP5 (MAL 13P1.274/ CAD52675), PP7 (PF14_0224/ AAN36837). Two bacterial-like PPPs (PF14_0660/Q8I5Y5 and PFL0300c/ Q8IKE5) were also identified in the $P$. falciparum genome. Besides 17 serine/threonine protein phosphatases, the $P$. falciparum genome includes sequences encoding dual-specificity protein phosphatase DSP (PFC0380w/CAB11119) and only one protein tyrosine phosphatase PTP (PF11_0139/ AAN35723) (Table 1).

\section{PfPP1}

PP1 is one of the most extensively investigated and ubiquitously present protein phosphatases. The initial function of PP1 was established in regulation of glycogen metabolism, but later its role has been demonstrated in several cellular processes, including cell division, muscle contractility, transcription, translation and apoptosis [50]. The amino acid sequence of PP1 from a variety of eukaryotic organisms is highly conserved. Two PP1 homologues namely PF14_0142 and PF14_0630 ( $\mathrm{PP} \alpha)$ were identified in the P. falciparum genome. Both homologues are localized on chromosome 14. The first report on functional characterization of PfPP1 was made by Yokoyama et al. [51], who demonstrated a PP1-like phosphorylase phosphatase activity in the P. falciparum extracts. Both infected erythrocytes as well as the freed parasite obtained by saponin lysis were found to contain significantly higher PP1-like activity as compared to the erythrocytes ghosts. PfPP1 with a deduced 304 amino acid sequence has been cloned from $P$. falciparum [20, 41]. PfPP1 contains the PPP signature sequence LRGNHE and two putative protein kinase $\mathrm{C}$ and five putative casein kinase phosphorylation sites. PfPP1 rescued a low glycogen phenotype glc7 (PP1-) mutant of Saccharomyces cerevisiae in functional complementation studies [20]. PfPP1 (PF14_0142) lacks a characteristic short proline-rich region at $\bar{C}$-terminus. PfPP1 has been cloned and overexpressed in E. coli. Functional characterization of the purified recombinant protein exhibited Ser/Thr as well as Tyr phosphatase activity. The toxins tautomycin, I1, I2, and okadaic acid inhibited PfPP1 with low $\mathrm{IC}_{50}$ values. The sensitivity of PfPP1 to these inhibitors may be attributed to the conserved sequence which creates a loop between the $\beta 12$ and $\beta 13$ regions of PfPP1 [43]. Other residues responsible for interaction with I-2 are: E52, E54, D164, E165 and K166 (Fig. 2) [41]. PfPP1 is a crucial element in mitotic division in P. falciparum and enables appro- 
Table 1. Serine/Threonine Protein Phosphatase (PPP) Catalytic Subunits Identified on Plasmodium falciparum Genome. Data Obtained from GenBank and PlasmoDB (www.Plasmodb.org) Data-Bases (Representatives of PTP and DSP Classes are also Included)

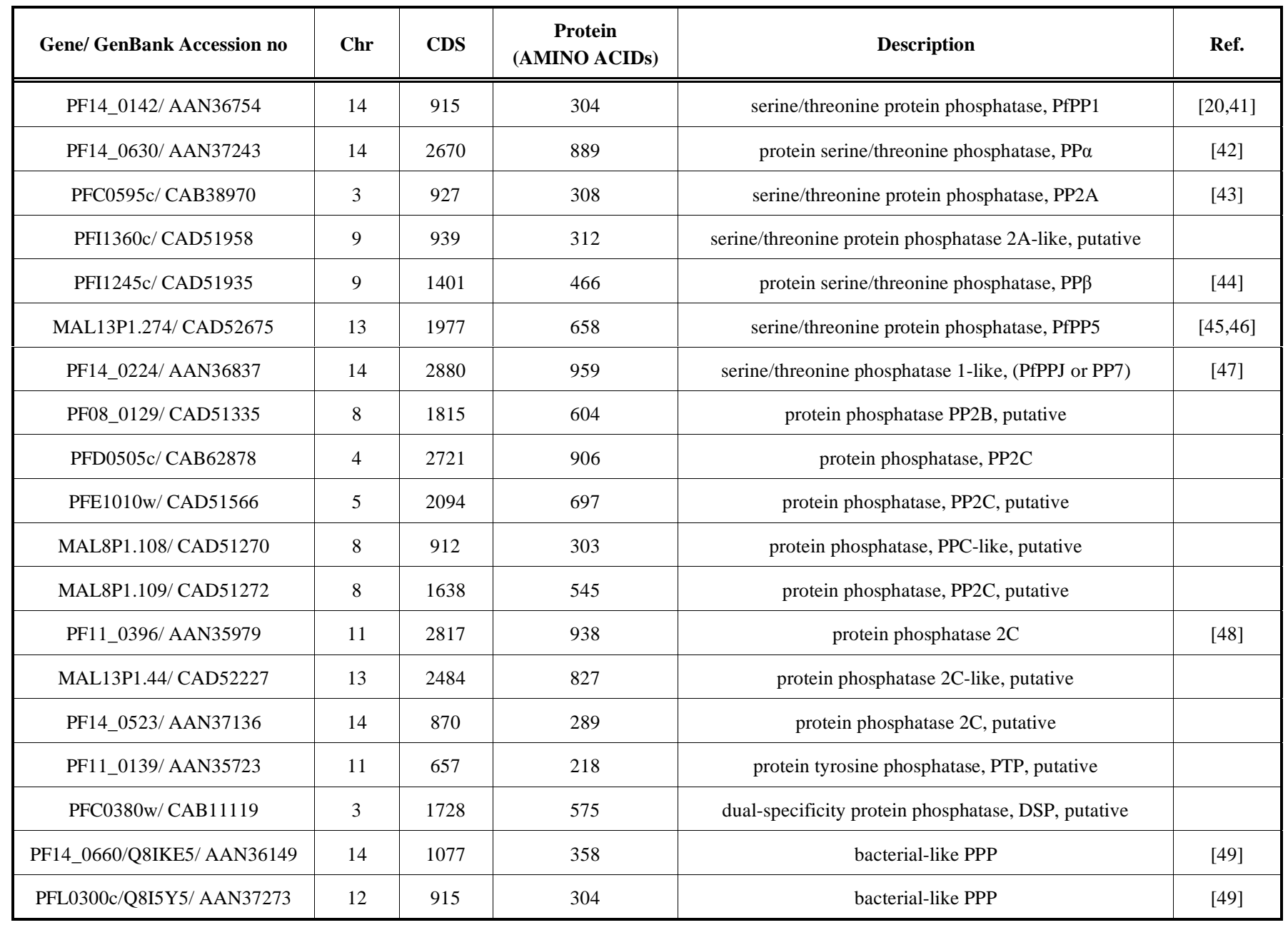

priate merozoite stage development [20, 52]. PfPP1 was reported to modulate the phosphorylation status of $P$. falciparum skeletal binding protein (PfSBP1) at the late intraerythrocytic development of the parasite and affects release of merozoites [44]. Further, Western blotting and immunofluorescence analysis revealed the localization of PfPP1 in the lumen of the Maurer's clefts, a Golgi-like secretory compartment transposed by $P$. falciparum into the cytoplasm of the host's erythrocyte [52]. Thus, PfPP1 is exported to the host's erythrocytes and plays an important role in the release of merozoites from the mature, infected erythrocytes [52]. PfPP1 is almost uniformly expressed in all the developmental stages of $P$. falciparum including rings, trophozoites, schizonts and late as well as early sexual stages [41]. However, the studies with high-density oligonucleotide arrays to generate expression profiles of human and mosquito stages of the malaria parasite's life cycle [53] has indicated differential expression profiles of PfPP1. Expression was highest in early and late schizogony with an abrupt decline of PfPP1 expression in merozoites (the data posted at www.plasmodb. org) (Fig. 5). This expression profile correlates with the role of PfPP1 in the release of merozoites [52]. The essential role of PfPP1 in survival of the parasite was confirmed by the phenotypic gene knockdown of the PfPP1 function in the erythrocytic $P$. falciparum stages using siRNA [41].

\section{PfPP $\alpha$}

PfPP $\alpha$ (PF14_0630) has the catalytic domains that are closely related to PP1 [54]. The amino acid sequence of PP $\alpha$ is very well preserved between Plasmodium species and identity between them ranges from 85 to $83 \%$. $\operatorname{PfPP} \alpha$ has the longest $\mathrm{N}$ terminal among serine/threonine protein phosphatases. That segment over 500 amino acids long is rich in serine $(8.5 \%)$, asparagines $(9.5 \%)$ and threonine $(6.2 \%)$ and composed of kelch-like repeats. These elements of PfPP $\alpha$ might be involved in protein-protein interactions [54]. The $\operatorname{PfPP} \alpha$ C-terminal sequence retained all characteristic domains of PP1. In addition, the catalytic part of PfPP $\alpha$ contains a proline-rich motif and five additional unusual inserts which may not have a strong influence on catalytic function of this enzyme. PfPP $\alpha$ contains conserved domains responsible for substrate binding, a catalytic site, and $\mathrm{Mn}^{2+}$ and $\mathrm{Fe}^{2+}$ binding sites. The N-terminal region of $\operatorname{PfPP} \alpha$ is not related to any known PPP, and these features place PfPP $\alpha$ into a unique category within PPP family [42]. Northern blot 


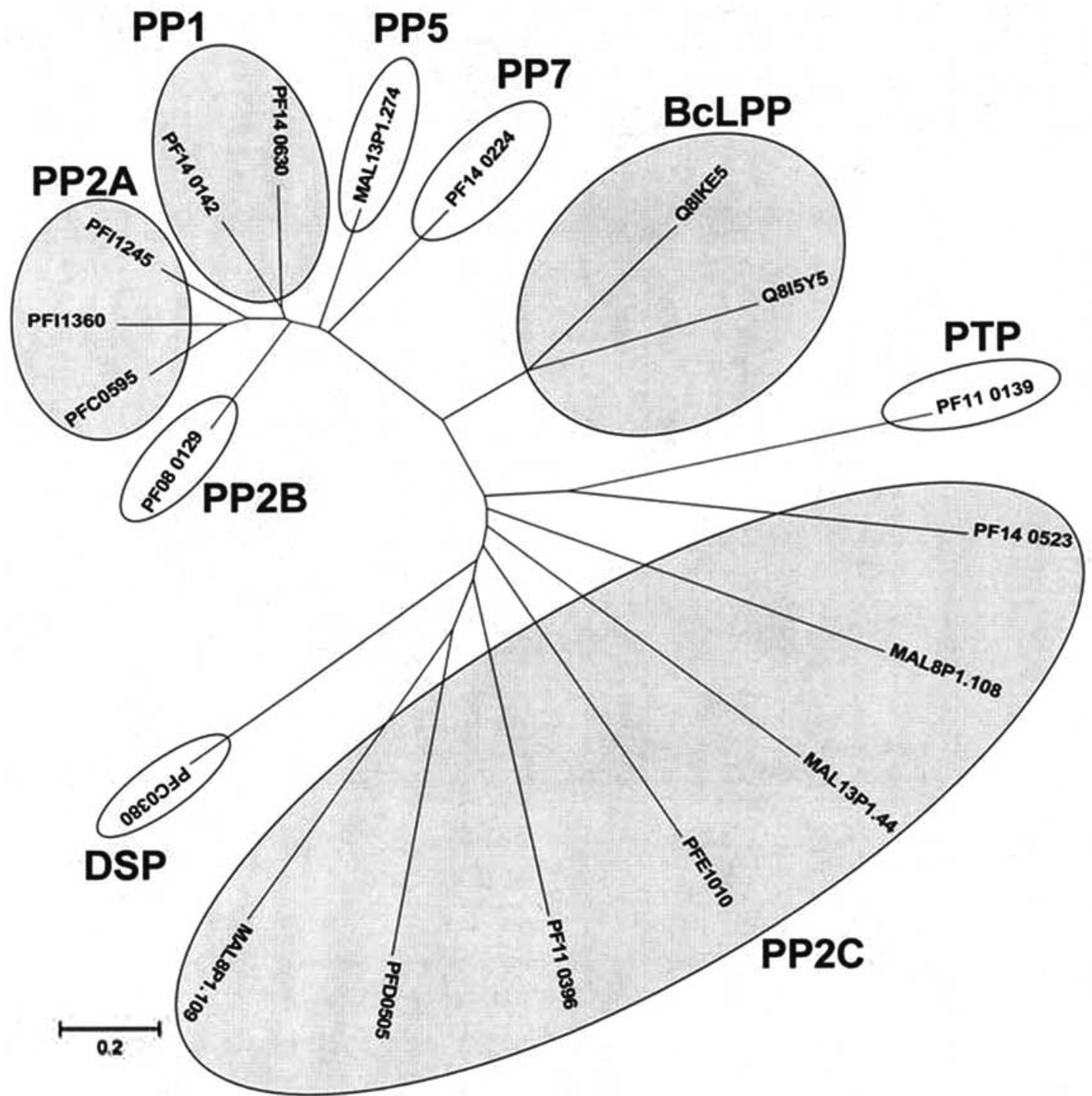

Fig. (4). The phylogenetic tree of serine/threonine protein phosphatases catalytic subunits of Plasmodium falciparum. Primary amino acid sequences of the PPPs analyzed are listed in Table 1. The sequences were analyzed by MEGA 4.0 version [109]. BcLPP- Bacterial-like protein phosphatases (Representatives of PTP and DSP Classes are also Included).

analysis detected PfPP $\alpha$ transcripts only in sexual stages of the parasite indicating its role in sexual stage specific functions. Affymetrix expression data (www.plasmodb.org) have also shown that the level of $\operatorname{PfPP} \alpha$ mRNA reaches a maximum of expression during the sexual stage (gametocyte) (Fig. 5).

\section{PfPP2A AND PfPP2B}

Analysis of PPP sequences in $P$. falciparum genome revealed three members of the PP2A family encoded by the genes PFI1245c, PFC0595c and PFI1360c. Their amino acid sequences aligned to human PP2A showed $54 \%, 55 \%$ and $57 \%$ identity, respectively. Interestingly, the homology of PfPP2As with human PP2A is significantly lower, as compared to the PfPP1 and HsPP1. The members of the PP2A family can be recognized by the signature motif YRCG, which distinguishes the PP2A from the PP1 group. This characteristic conservative domain is responsible for high sensitivity of PP2A to okadaic acid. A PPP encoded by
PFI1245c has earlier been characterized as PfPP $\beta$ [44]. The gene localized on chromosome 9 has an unusual intron with four repeats of 32 nucleotides, which displays high degree of size polymorphism among different isolates of $P$. falciparum [44]. In spite of two distinct domains, the PfPP $\beta$ sequence was placed under the PP2A family of PPPs on the basis of the significant similarity of the C-terminal 315 amino acid domain with the catalytic subunit of the PP2A. Northern blot analysis has shown the highest expression of PP2 $\beta$ in the sexual erythrocytes stage [44], while Affimetrix expression analysis indicates the highest expression not only in gametocytes but also in late trophozoites (www.plasmodb.org) (Fig. 5). This protein has an extension of 151 amino acids at the $\mathrm{N}$-terminus, which contains putative phosphorylation sites, and five additional amino acids between $\beta 7-\beta 8$ strands; the catalytic domain of PfPP $2 \beta$ is almost identical to other PfPP2As [44]. The N-terminus sequence probably plays a regulatory function by reversible phosphorylation. The cDNA corresponding to the gene PFC0595c was isolated by 


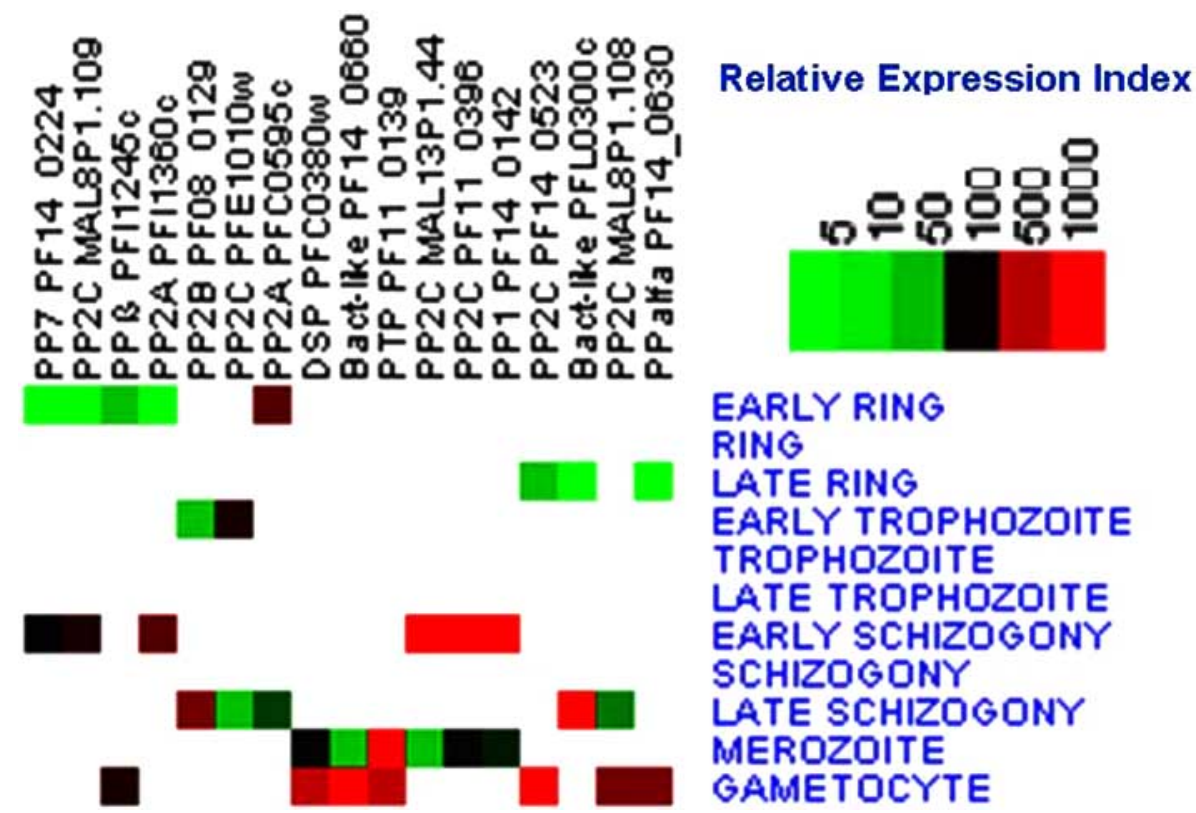

Fig. (5). Hierarchical clustering (HCE3.5-Power) - complete linkage analysis. Maximal and minimal expression levels of serine/threonine protein phosphatases transcripts in different life-cycle developmental stages of Plasmodium falciparum. The heat map was generated from the Affymetrix gene expression data posted at PlasmoDB. The links for all Plasmodium microarray data are available at http://plasmodb.org/ common/microarrays.

Dobson et al [43]. PfPP2A showed typical attributes of a PP2A enzyme: potent phosphatase activity against the $\alpha$ subunit of phosphyrylase kinase, high sensitivity of the enzyme to okadaic acid, activation by $\mathrm{Mn}^{2+}$ and resistance to inhibitor-1 (Fig. 3) [43]. Between all known PfPP2A the protein encoded by the PFI1360c gene has the highest $(57 \%)$ identity with the human PP2A sequence. A substitution of the crucial residue $\mathrm{L} 312 \mathrm{~S}$ which is methylated in the posttranscriptional process raises a question on influence of this methylation on the activity of this enzyme.

The two more PPPs namely, a $\mathrm{Ca}^{+2}$-activited PfPP7 (PF14_0224) and PfPP2B-calcineurin (PF08_0129) were also identified in P. falciparum [47]. PfPP7 has been described earlier as a member of the PP1 family named PfPPJ [22]. The amino acid sequence predicted by Dobson et al [22] was a core catalytic region of PfPP7. PfPP7 undergoes post-translational processing which results in proteolytic cleavage of PfPPJ between Ser531 and Gly534 [50]. The amino acid sequence from PlasmoDB consists of 959 amino acid residues. Besides two predicted proteolytic cleavage sites, PfPP7 also has two EF hand-calcium binding domains in the $\mathrm{C}$ terminus. Additional analysis has shown the possible existence of an IQ motif - calmodulin binding (80-105 aa) in the $\mathrm{N}$ terminal region. Calcium and manganese cations are indispensable to establish full activity of that enzyme. PfPPJ as opposed to the rest of the PP1 family is not very sensitive to the inhibitors $\mathrm{OA}$ and $\mathrm{I} 2\left(\mathrm{IC}_{50} 1 \mu \mathrm{M}\right.$ and $0.1 \mu \mathrm{M}$, respectively) [22]. There are substitutions in the residues responsible for $\mathrm{I} 2$ inhibitor binding and in a segment interacting with OA (Fig. 2).

$\mathrm{PP} 2 \mathrm{~B}$-calcineurin $(\mathrm{CN}$,$) is another protein phosphatase$ which depends on $\mathrm{Ca}^{+2}$ for catalytic functions. $\mathrm{CN}$ creates a holoenzyme assembly of a catatytic subunit A (CnA) (MW $70 \mathrm{kDa})$ and a regulatory subunit $\mathrm{B}(\mathrm{CnB})(\mathrm{MW} 20 \mathrm{kDa})$. The amino acid sequence of $\mathrm{CN}$ encloses a core region from
43 to 285, which is characteristic for all PPPs (Fig. 2). However, the C-terminus contains CaM- (calmodulin) binding domain and $\mathrm{CnB}$-binding domain, which are separated by an insert from 43 to 285 . $\mathrm{N}$ - and $\mathrm{C}$ - termini in PfPP2B play regulatory roles, similar to that shown for other PPPs. The existence of an auto-inhibitory (AI) domain at $\mathrm{C}$ terminus has also been suggested [47]. The antimalarial activity of cyclosporine A was demonstrated more than 25 years ago. The complex consists of cyclophilins ( $P$. falciparum encodes Cyp19, Cyp22 and Cyp24) and cyclosporin A inhibit the activity of CN $[47,55]$.

\section{PfPP5 (THE NUCLEAR PPP WITH TETRATRICO- PEPTIDE REPEATS)}

A gene encoding the P. falciparums PP5 homologue was identified on chromosome 13. According to the NCBI database, PfPP5 (MAL13P1.274) is a 658 amino acid protein, while separately Dobson and Lidenthal obtained proteins that were 64 amino acid shorter (AAL15170 and AAK95648) $[45,46]$. The amino acid sequence of these three proteins is almost identical except an extension at $\mathrm{N}$ terminus in MAL13P1.274. The function of this segment is unknown. In higher eukaryotes, PP5 is considered as a multifunctional protein, which interacts with the glucocorticoid receptor, hsp90 hetrocomplex, subunit A of PP2A, DNA dependent kinase (DNA repair process) and growth arrest mediated by p53 [56, 57]. In Arabidopsis PP5 is involved in light-dependent signal transduction [58]. The amino acid sequence of PfPP5 has an extended N-terminus, which has no homology to any other known PPs $[45,46]$. The catalytic domain of PfPP5 showed 75\% similarity to PP5. Presence of four characteristic tetratricopeptide repeats (TPRs) confirmed the identity of PfPP5. The TPRs create a cradle-like structure, which can take part in protein-protein interactions [45]. The TPR domain is responsible for auto-regulation of 
phosphatase activity. Polyunsaturated fatty acids like arachidonic and oleic acid interact with these regions and activate the enzyme. However, activation of PfPP5 with unsaturated fatty acids was less pronounced compared to other PP5s [46]. PfPP5 shows high intrinsic activity as confirmed with recombinant protein isolated from overexpressing $E$. coli cultures as well as native enzyme isolated from the parasite extracts. PfPP5 attains low autoinhibition due to a difference in the C-terminal region which affects interaction between TPRs and the C-terminal region [46]. These distinct characteristics of the PfPP5 may be important in design of selective inhibitors against the parasite enzyme. PfPP5 also interacts with Pfhsp90, an ortholog of mammalian hsp90, through TPRs. The TPR region is followed by a hypothetical nucleus targeting domain (NLS-BP). The primary sequence of PfPP5 retains a conserved SAPNYC domain, which makes it sensitive to OA [45, 46]. The transcripts for PfPP5 have been found in all asexual stages, and the protein was predominantly localized to the parasite nucleus [46]. Similar to other eukaryotic PP5 orthologs, the PfPP5 might be a part of DNA repairing complex, as may be predicted by its nuclear localization.

\section{PfPP2C $\left(\mathrm{Mg}^{2+}\right.$-DEPENDENT PP)}

Relatively little is known about plasmodial $\mathrm{Mg}^{2+}$ - dependent protein phosphatases PP2C. Seven genes, which putatively encode for PP2C homologues, have been identified in the $P$. falciparum genome. However, only one of them (PF11_0396) has been studied in detail [48]. PF11_0396 encodes for a protein with 920 amino acids, which is almost twice of other PP2Cs. PfPP2C can be divided into two halves, the $\mathrm{N}$ - and C-terminal, each with a complete PP unit termed as Pf2C1 and Pf2C2, respectively. PfPP2C likewise yeast PP2C might be involved in stress response by MAPK cascade. The native functionally active PfPP2C was characterized as a dimer with four catalytic units on two sub-units. Each half, when expressed independently, was catalytically active and complemented the heat shock response defect of a Schizosaccharomyces pombe mutant with a PP2C deletion. It was also determined that PfPP2C influences transcription and translation by dephosphorylation of the $\beta$ subunit of RNA polymerase II and elongation factor $\beta(\mathrm{EF}-\beta)$ [59].

\section{BACTERIAL-LIKE PROTEIN PHOSPHATASES IN PLASMODIUM FALCIPARUM}

Serine/threonine protein phosphatases of bacterial origin are present in Plasmodium spp genomes [59]. Unlike the eukaryotic PPP family, the bacterial PPPs have broad substrate specificity. The presence of bacterial-like PPPs has been shown in the genomes of protozoa as well as plants. The bacterial-like PPP have been divided into three groups: Rhilpha (Rhizobiales/ Rhodobacteria/ Rodospirillaceae-like phosphatases), Shelphs (Shewanella-like phosphatases) and Alphs (diadenosine tetraophosphatases ApaH-like phosphatases). The two Arabidopsis thaliana genes (At3g09960 and At3g09970) can be designated as Rhilpha phosphatases and two genes (At1g07010 and At1g18480) belong to the Shelphs group. This group also includes the bacteria-like phosphatases identified in P. falciparum (PF14_0660/Q8I5Y5 and PFL0300c/Q8IKE5) and P. yoelli (Q7RIH8 and Q7RR22).
The bacteria-like PPPs have considerable differences in primary structures from 'regular' eukaryotic serine-threonine protein phosphatases. The bacterial-like PPPs do have Nand C-terminal extensions like eukaryotic members of PPP. The beginning sequences are significantly conserved in Rhilpha and Shelphs, with variations mainly in the inserts between conserved motifs GNHE and H(A/G)G. Instead of the characteristic eukaryotic PPP motif SAPNY, the bacterial-like PPP sequences contain the $(\mathrm{I} / \mathrm{LV}) \mathrm{D}(\mathrm{S} / \mathrm{T}) \mathrm{G}$ motif. Interestingly, in the sequences of bacteria-like PPPs, the amino acids responsible for metal ion binding (such as Asp62, His66, Asp92, His173 and His248) are conserved [60]. Furthermore, the Gly residue always occurs after His248. Members of Rhilpha have been found only in land plant genomes. Andreeva and Kutuzov [49] suggested that some Rhizobiales could share their genes by horizontal transfer. Genomes of fungi, plants, red alga, apicomplexa and trypanosomatids contain genes encoding Shelphs. All taxonomic groups mentioned above (except fungi and trypanosomatids) have plastids (e.g., chloroplasts or apicoplasts), which originated form cyanobacterial ancestors [61, 62]. Unexpectedly, Shelphs have not been found in cyanobacterial genomes, which mean that they could have other ancestors [59]. None of the bacterial-like PPPs identified in the genomes of Plasmodium spp have been studied at the functional level. According to Affymetrix microarray results, genes PF14_0660 and PFL0300c reach their maximum expression in the late schizogony and gametocyte stages, respectively (Fig. 5). This indicates that their expression pattern does not differ from most other PfPPPs. In view of the potential unique molecular characteristics of the bacteriallike PPPs identified in malarial genomes and the absence of the homologs in mammalian genomes, it would be interesting to study their role in the parasite and their exploitation as potential targets for new antimalarial drug discovery.

\section{EXPRESSION, REGULATION AND FUNCTIONS OF PPPS IN PLASMODIUM FALCIPARUM}

The data on differential expression profiles of all the PPP genes identified in $P$. falciparum genome was compiled from the microarray transcription profiles of the individual genes available at PlasmoDB (www.plasmodb.org) (Fig. 5). The expression profiles of selected PPP genes, which have been functionally characterized in $P$. falciparum, were also compared. This information would be important in predicting the role/function of individual PPPs in the parasite. In view of complex life cycle of the malaria parasite, PPPs are likely to have a highly sophisticated role to play for functional regulation and control of different genes related to the cell cycles. It has been clearly demonstrated that there are specific sets of genes which are turned on or off during the developmental cycle of the malaria parasites [63]. The malaria parasite has been indicated to have a hardwired transcriptome [64]. The mechanisms of regulation of gene expression in $P$. falciparum apparently vary from other eukaryotic species and are still incompletely understood [64]. In view of this, the posttranslational modification of proteins, including reversible phosphorylation and dephosphrylation through kinases and phosphatases, bear a greater responsibility for regulation of protein functions. Despite severe stress exerted by immunological and cellular defense machinery of the host, the 
parasite is able to get through the highly organized processes of cellular and molecular development. The PPP expression profiles compiled from microarray gene expression data from PlasmoDB indicated significant differences in the intraerythrocytic developmental cycle of the parasite (Fig. 5). Most of the PPP encoding genes showed stage-specific regulation of their expression. It is noteworthy that initial developmental stages from early ring to late trophozoite demonstrate a low level of PPP expression, while in two late stages significant increase in PPP expression were observed: the early schizogony (PP1 PF14_0142, PP2A PFI1360c, PP7 PF14_0224, PP2C PF11_0396, PP2C MAL8P1.109, PP2C MAL13P1.44) and sexual intraerythrocyte stage gametocyte (PP $\alpha$ PF14_0630, PP $\beta$ PFI1245c, PP2C MAL8P1.108, PP2C PF14_0523, bacteria-like PPP PF14_0660, PTP PF11_0139 and DSP PFC0380w) (Fig. 5). These data indirectly suggest that the parasite develops a signal transduction net during the later stages of cell cycle and prepare for release of merozoites, which come in contact with the environment out of RBCs. The gene PfPP1 (PF14_0142) reaches the highest expression level in early schizogony and then quickly declines in the merozoite stage. Recently, Blisnick et al. [52] revealed that PfPP1 plays an important role in release of mature merozoites. Indirectly, this has been confirmed by the presence of a high level of mRNA encoding Pf PP1 (PF14_0142) in the schizogony. Contrary to this, another study reported the presence of constant level of PfPP1 mRNA and protein in different developmental stages of the parasite [65]. The glycogen synthase kinase 3 (PfGSK3) is responsible for phosphorylation and the PfPP1 for dephosphorylation of Pf skeleton-binding protein 1 (PfSBP) located in Maurer's cleft. The Maurer's clefts are secretory structures which are the part of the parasite's machinery involved in translocation of the parasite's proteins to RBC membranes. PfSBP1 is committed in that process. The PfSBP1 interacts with PfPP1 by its PP1 docking motif. Neither PfSBP nor PfPP1 possess a signal peptide which could transport them to the Maurer's cleft. Involvement of this process in translocation of other parasite proteins has also been proposed [44].

Few proteins have been characterized from $P$. falciparum which regulate the catalytic functions of PPP in the parasite. A protein with leucine rich repeat motifs (PfLRR1) was identified in P. falciparum. PfLRR1 was identified as a homolog of suppressor of dis2 $\left(s d s 22^{+}\right)$from $S$. pombe, which is an essential regulator of cell division in the yeast. Deletion of sds $22^{+}$caused mitotic arrest, and the mutant yeast stayed in the metaphase $[65,66]$. PfLRR 1 showed $42 \%$ identity and $61.5 \%$ similarity to the yeast $\mathrm{Sds} 22^{+}$. PfLRR1 was found to interact with PfPP1 and form a complex. A PfLRR1-PfPP1 complex was also isolated from the parasite extracts, and interaction of PfLRR1 with PfPPI was found to cause inhibition of phosphatase activity of the enzyme. This observation was in contrast to the effect of $\operatorname{sds} 22^{+}$on the yeast PP1, which regulates the cell cycle in $S$. pombe by activation of PP1. PfLRR1 interacted with PfPP1 but not with PfPP2A, indicating its role in selective functional regulation of PfPP1. Both PfLRR1 and PfPP1 are localized in cytoplasm and the nucleus. In contrast to the yeast experiment, PfLRR1 regulated PfPP1 by inhibiting the phosphatase activity. Xenopus oocytes are physiologically arrested at the G2/M meiotic prophase I, which can be overcome by treatment with OA, anti-PP1 antibodies or microinjected mRNA of PfLRR1 [65, 67]. Microinjection of PfLRR1 capped mRNA (cRNA) into the oocytes resulted into appearance of germinal vesicle breakdown, and was accompanied with down regulation of PP1 activity. Interaction of PfLRR1 with PP1 in the oocytes was also confirmed by immunoblot analysis. Role of physiological inhibitors in control and regulation of PPP activities was established [68]. A unique aspartate rich protein (ARP), which strongly inhibits PfPP2A, has been identified as a potential physiological regulator of PfPP2A [68]. PfARP was found to cause selective inhibition of PfPP2A with no effect on PfPP1, PfPP2B, PP5 or PfPPJ.

\section{INHIBITORS OF PPPS: MOLECULAR TOOLS AND THERAPEUTIC APPLICATIONS}

Conclusive evidences regarding role of PPPs in regulation of multiple cell processes have generated considerable interest and significant attention to the inhibitors of these enzymes. Several inhibitors active against specific isoforms of PPPs have been identified. Identification of selective PPP inhibitors has provided useful tools to investigate the functions of specific PPP isoforms [69]. The selective inhibitors of PPPs also have significant therapeutic implications.

\section{THE ENDOGENOUS PPP INHIBITORS: THE MO- LECULAR SWITCHES}

Regulation of PPPs in vivo is primarily attained through expression and functions of endogenous proteinaceous inhibitors of PPPs (Table 2) [70]. Characterization of the endogenous PPP inhibitors has been useful in understanding the regulation of individual isoforms of PPPs and their functions in different cellular processes. All endogenous inhibitors of PPPs are phosphoproteins and the PP inhibitory potencies of these proteins are controlled through their phosphorylation/dephosphorylation. The endogenous intracellular inhibitors of PPPs function as additional regulatory switches in the cascade of PPP-associated signal transduction cascades and regulation of cellular and metabolic functions [70]. The catalytic subunit of PP1 binds to a number of regulatory subunits, which target the enzyme to proximity of their physiological substrates [71]. Additional regulation of PP1 can be achieved through their inhibition with different intracellular proteins. PP1 is inhibited by several heat-stable inhibitor proteins, which include inhibitor- 1 , its neuronal analogue, DARPP-32, and inhibitor-2 [70]. Inhibitor-2 is constituted as a subunit of the $\mathrm{Mg}^{2+}$-dependent PP1 (PP1M or PP1I), which is an inactive form of the enzyme. PP1I is transiently activated when IPP-2 in the complex is phosphorylated at threonine-72 position by GSK-3 (Fig. 6). This suggests the role of IPP-2 as a molecular chaperone. Inhibitor-1 and DARPP-32 are both inhibitory only when phosphorylated by cAMP-dependent protein kinase. In addition, PP1 is potently inhibited by ubiquitously expressed nuclear protein Nuclear Inhibitor of Protein Phosphatase 1 (NIPP-1) which is the most potent inhibitor of PP-1 characterized so far $\left(\mathrm{IC}_{50}<1 \mathrm{pM}\right)$ [72]. Additional endogenous inhibitors of PP1, referred as IPP3 [73], IPP4 [74] and now most recently IPP 5 [75], have also been characterized. The regulation of activity of the catalytic subunit of PP1 with these endogenous inhibitors should allow PP1 to dephosphorylate thou- 
Table 2. Endogenous Inhibitors of Serine/Threonine Protein Phosphatases

\begin{tabular}{|c|c|c|c|}
\hline Inhibitor & Synonym; Property & PP Target & Reference \\
\hline G-Substrate & Protein kinase G substrate; Regulator of PP2A in Purkinje cells & $\mathrm{PP} 1 ; \mathrm{PP} 2 \mathrm{~A}$ & [80-82] \\
\hline DARPP-32 & The dopamine- and cAMP-regulated Phosphoprotein; neuronal analog of IPP-1 & PP1 & {$[70]$} \\
\hline Inhbitor-2 & $\begin{array}{l}\text { IPP- } 2 \text {; Forms a stable and high affinity complex with PP1c termed as the ATP- } \mathrm{Mg}^{2+} \text {-dependent } \\
\text { phosphatase }\end{array}$ & PP1c & {$[70]$} \\
\hline Inhibitor-3 & IPP-3; hemochromatosis candidate gene V (HCG V) & PP1 & [73] \\
\hline Inhibitor-4 & IPP-4; I-2-related PP-1 inhibitor protein & PP1c, PP1M & [74] \\
\hline Inhibitor-5 & IPP-5; human inhibitor-5 of protein Phosphatase & PP1c & {$[75]$} \\
\hline CPI17 & 17-kDa PKC-potentiated inhibitory protein of PP1 & PP1 & [83] \\
\hline $\mathrm{I}-1^{\mathrm{PP} 2 \mathrm{~A}}$ & $\begin{array}{l}\text { Heat-stable protein, I-1 PP2A; Putative histocompatibility leukocyte antigen class II associated } \\
\text { protein-1(PHAP-I); mapmodulin, pp32; Leucine- Rich Acidic Nuclear Protein (LANP) }\end{array}$ & PP2A & {$[76]$} \\
\hline $\mathrm{I}-2^{\mathrm{PP} 2 \mathrm{~A}}$ & $\begin{array}{l}\text { Heat stable PP2A inhibitor; Homologue of the human SET } \alpha \text {; PHAP-II; Template Activating } \\
\text { Factor-1 } \beta \text { (TAF-1 } \beta)\end{array}$ & PP2A & [76] \\
\hline FKBP3 $8^{\mathrm{b}}$ & Immunophilin; Mitochondrial FK506 binding protein & Calcineurin (PP2B) & {$[78]$} \\
\hline Calcipressin-1 & Calcineurin binding protein-1 & Calcineurin (PP2B) & [81] \\
\hline
\end{tabular}

${ }^{\mathrm{a}}$ Putative homolog identified in P. falciparum genome (PF10_0311 PlasmoDB).

${ }^{\circ}$ Homolog characterized in P. falciparum (PfFKB35) [78]; (PFL2275c PlasmoDB).

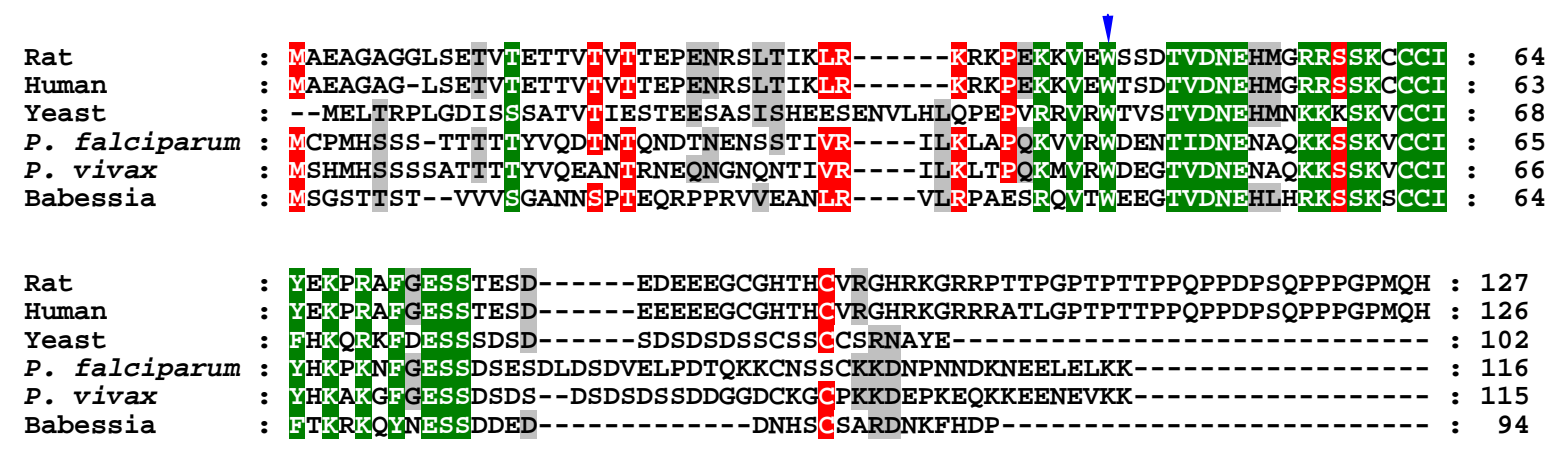

Fig. (6). Alignment of amino acid sequences of PP1 protein phosphatase inhibitor-1 (IPP-1). The conserved phosphorylation site (Tryptophan) of IPP-1 is indicated by arrow. Rat- EDL84611; Human- NP_068778; Yeast-CAB11073 (Schizosaccharomyces pombe); Plasmodium falciparum- PF10_0311/ XP_001347595; Plasmodium vivax- EDL42429; Babesia bovis- EDO08407.

sands of proteins, involving independent regulatory mechanisms. Regulation of PP2A activity occurs through different specific endogenous inhibitor proteins referred as I- $1^{\mathrm{PP} 2 \mathrm{~A}}$ and $\mathrm{I}-2^{\mathrm{PP} 2 \mathrm{~A}}[76]$. Both $\mathrm{I}-1^{\mathrm{PP} 2 \mathrm{~A}}$ and $\mathrm{I}-2^{\mathrm{PP} 2 \mathrm{~A}}$ inhibit PP2A by direct binding with the catalytic sub-unit. The putative histocompatibility leukocyte antigen class II-associated protein1 (PHAP-II) and I- ${ }^{\text {PP2A }}$ are identical proteins. The I-1 ${ }^{\text {PP2A }}$ has been localized to the cytoplasm or nucleus, depending on the cell types, while I-2 ${ }^{\mathrm{PP} 2 \mathrm{~A}}$ is localized mostly in the nucleus.
The proteins binding to FK506 (tarcolimus), an immunosuppressant belonging to a class of immunophilins, are commonly known as FKBPs (FK506 binding proteins). The FK506-FKBP complexes bind and inhibit calcinurine, a $\mathrm{Ca}^{2+}$-calmodulin-dependent serine/threonine protein phosphatase (PP2B). However, unlike other FKBPs, a mitochondrial FK506-binding protein 38 (FKBP38), was demonstrated to bind and inhibit calcineurin in the absence of the FK506. These observations suggest FKBP38 as an inherent 
inhibitor of PP2B [77]. A homolog of FKBP38 has been characterized from $P$. falciparum [78]. The malarial homolog PfFKBP35 like other immunophilins also contains tetratricopeptide repeats (TPR) and has a peptidyl prolyl cis-trans isomerase (PPIase) activity that is sensitive to both FK506 and rapamycin. PfFKBP35, like FKBP38 also significantly inhibits PfCN (malarial calcineurin) in vitro in the absence of any drug. FKBP35 is the only immunophilin identified in $P$. falciparum genome. The essential role of PfFKBP35 as a chaperone and the important differences between PfFKB35 and FKB38 indicate this protein as a potential target for new antimalarial drug discovery. A calcineurin binding protein (CBP-1) characterized from Cryptococcus neoformans was found the inhibit calcineurine activity in vitro [79]. CBP1 and other homologs from S. cerevisiae, S. Pombe, Droso- phila melanogaster, Caenorhabditis elegans and humans contain a signature motif SPPXSPP.

\section{SMALL MOLECULE INHIBITORS OF PPPS}

Protein phosphatases are excellent drug targets because they play crucial roles in cell processes as indispensable components of signal transduction. Inhibition of their activity causes strong impacts on cell processes. There are many well known small molecule inhibitors specific for PP1 and PP2A such as calyculin A, cantharidin, cantharidin analogues, microcystin LR, okadaic acid, tautomycin, fostriecin, cyclosporin A and endothall [85-92] (Fig. 7A). Interestingly, these inhibitors are more active against PP2A and PP1. Several specific inhibitors of PP2B such as cypermethrin, deltamethrin and fenvalerate have also been identified $[93,94]$

A

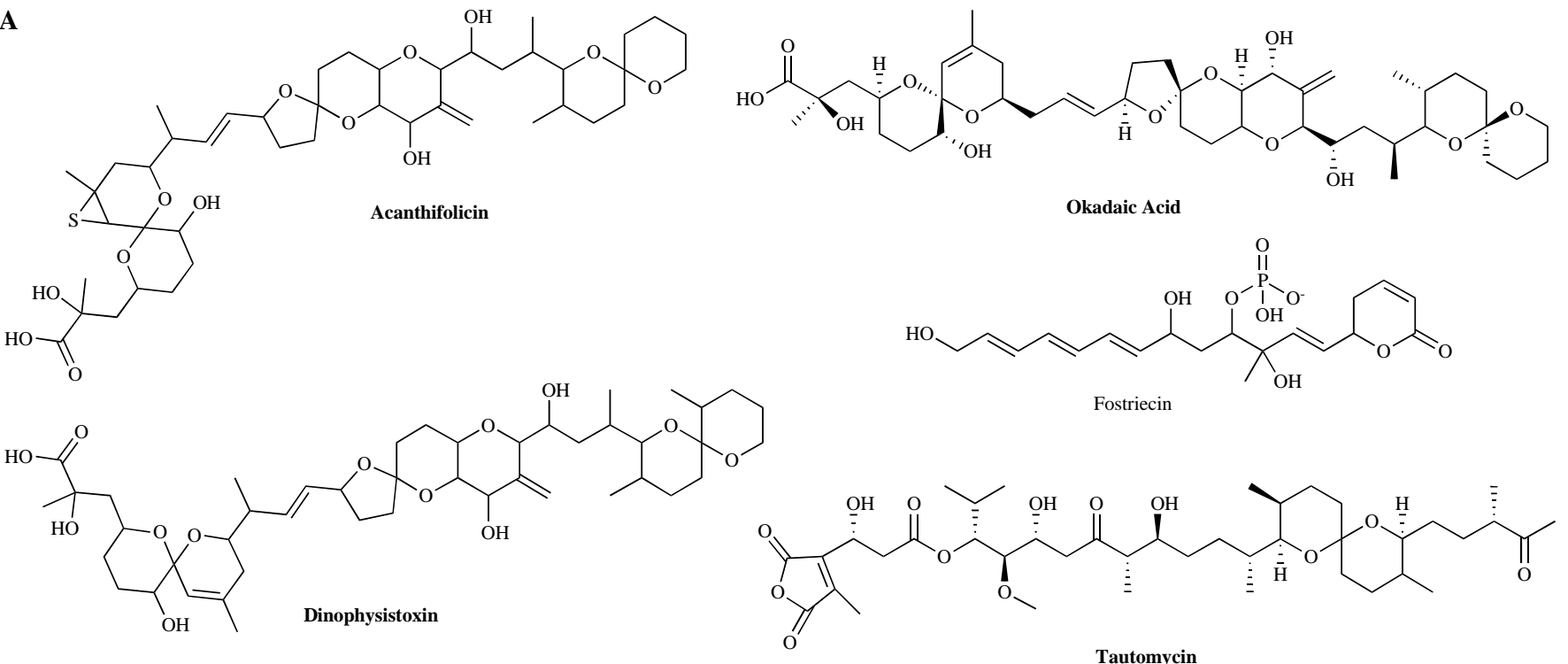<smiles>C/C=N\C(N)N</smiles><smiles>[R1]C(C)C#N</smiles><smiles>CC12C(=O)OC(=O)C1(C)C1(C)C3CCC(O3)C21</smiles><smiles>C/C=C(/C(=O)O)N(C)C(=O)CCC(NC(=O)C(C)C(/C=C/C(C)=C/C(C)C(Cc1ccccc1)OC)NC(=O)C(CCCN=C(N)N)NC(=O)C(C)C(NC(=O)/C(=C/C)C(C)C)C(=O)O)C(=O)O</smiles><smiles>CCC(C(=O)NC(C(=O)O)C(C)C(=O)NC(C(=O)NC(CCC(C)CC(C)C(Cc1ccccc1)OC)C(C)C)C(C)C(=O)NC(CCC(=O)N(C)C(CC)C(=O)O)C(=O)O)C(C)C</smiles><smiles>O=C(O)C1C2CCC(O2)C1C(=O)O</smiles><smiles>O=C1OC(=O)C2C3CCC(O3)C12</smiles>

Nodularin

Motuporin

Endothal
Cantharidin 
<smiles>C/C=C/C=C/C=C/C(O)C(C)C(CCC(C)C1OC(=O)C=CC1C)CP(=O)(O)O</smiles><smiles>CC1(C)C(C=C(Cl)Cl)C1C(=O)OC(C#N)c1cccc(Oc2ccccc2)c1</smiles>

Cypermethrin<smiles>CC1(C)C(C=C(Br)Br)C1C(=O)OC(C#N)c1cccc(Oc2ccccc2)c1</smiles>

Deltamethrin<smiles>CC(C)C(C(=O)OC(C#N)c1cccc(Oc2ccccc2)c1)c1ccc(Cl)cc1</smiles>

Fenvalerate<smiles>C=CCC(C=C(C)CC(C)CC(OC)C1OC(O)(C(=O)C(=O)N2CCCCC2C(=O)OC(C(C)=CC2CCC(O)C(OC)C2)C(C)C(O)CC(=O)C(CC=C)CC(C)C)C(OC)CC1C)C(=O)OC</smiles>

Tacrolimus (FK 506)

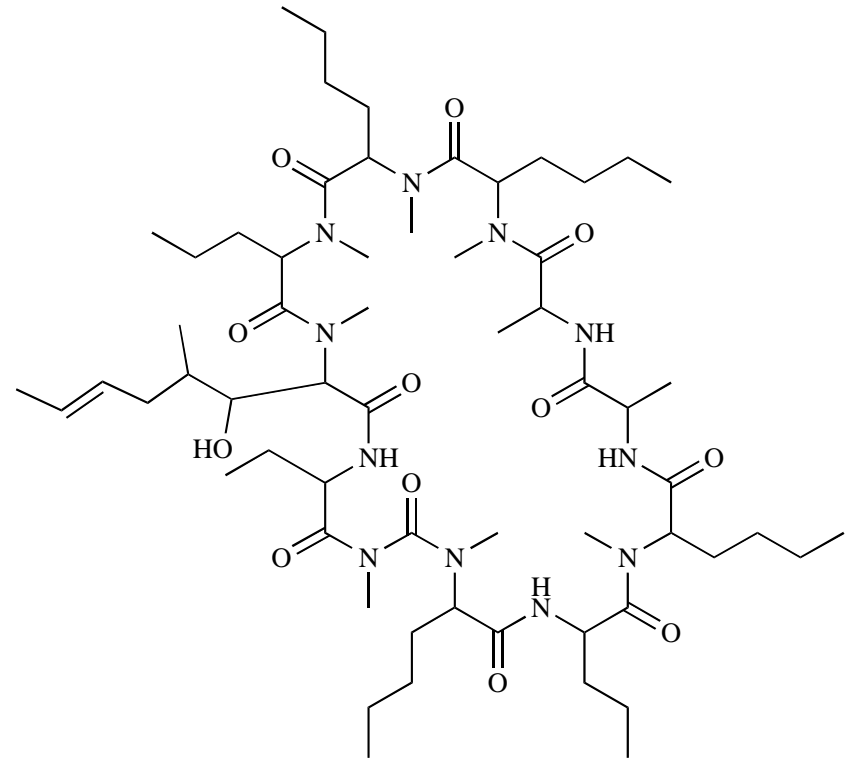

Cyclosporin A

Fig. (7). Structures of small molecular inhibitors of serine/threonine protein phosphatases (PPPs). A- Inhibitors of PP1 and PP2A; B- Inhibitors of PP2B.

(Fig, 7B). Their different inhibitory properties may facilitate discovery of new protein phosphatase features and better understanding of the processes that they influence. Most of the known small molecule inhibitors of PPPs cannot be directly use in clinical medicine because of their high cytoxicity [95]. The high cytoxicity is probably caused by high similarities between amino acid sequences of PPPs from different species. Nevertheless, there is considerable research in progress regarding synthesis of new analogs of PPP inhibitors, such as on cantharidin and fostriecin (FOC) [95]. Fostriecin is an antitumor antibiotic isolated from Streptomyces pulveraceous. The compound is not only an inhibitor of protein phophosphatases but also of topoisomerases II [96]. This antibiotic also interacts with other cell proteins
[97]. These features could make fostriecin a potent drug against cancer. Fostriecin interacts with the same site of the primary sequence of PPP as okadaic acid and cantharidin (the $\beta 12-\beta 13$ loop SAPNYC region) (Fig. 2) $[98,99]$. FOC inhibits PP2A with 40,000 fold stronger potency than inhibition of PP1 $\left(\mathrm{IC}_{50} 3.2 \mathrm{nM}\right.$ for PP2A v/s $131 \mu \mathrm{M}$ for PP1) [100]. The FOC went though preclinical and clinical studies. Although phase I and pharmacokinetic studies obtained positive results, further trials were stopped because of contamination of the drug. The situation could change because new methods for synthesis of fostriecin are now avialable [100]. Cantharidin is secreted by male blister beetles (order Coleoptera, family Meloidae) [101]. This agent is a strong inhibitor of PP1 ( $\left.\mathrm{IC}_{50} 473 \mathrm{nM}\right)$ as well as PP2A (IC $\left.{ }_{50} 40 \mathrm{nM}\right)$ [102]. 
Extensive research has been carried out with cantharidin and its derivates; especially their evaluation against carcinoma cells $[87,103,104]$. The main goal has been to obtain analogues with higher activity and specificity. Cantharidin treatment causes abnormal mitotic spindles, mitotic arrest, DNA damage, and apoptosis [105]. Cantharidin and its analogs have been tested against number of human cancer lines. These experiments have shown promising antitumor activity of cantharidin and some of its derivates [106]. Norcantharidin is the most potent cantharidin analog. Both of them possess features of a promising drug against leukemia. They do not cause myelosuppression. Many drugs against leukemia have developed multidrug resistance phenotype (MRP). Cantharidin is also active against these resistant cells [105]. In a clinical trial with norcantharidin and cantharidin, only cantharidin treatment induced nephrotoxicity as a side effect [107]. Recently some PP2A inhibitors have shown promising antimalarial activities in vitro against $P$. falciparum cultures. Okadaic acid, calyculin A and endothall inhibited the growth of $P$. falciparum in culture with $\mathrm{IC}_{50}$ values of $38.5 \mathrm{nM}, 9.9$ $\mathrm{nM}$ and $7.8 \mu \mathrm{M}$, respectively [42,108]. Evaluation of antiplasmodial activity of protein phosphateses inhibitors has not been a subject of intense research in the past. In view of the essential functions of PPP protein phosphatases, the inhibitors seems to be promising source of antiplasmodial drugs.

\section{NOTE ADDED}

While this manuscript was under review an article appeared online on current understanding of the structure, regulation and biological functions of protein Ser/Thr phosphatases in unicellular parasites [110]. This indicates increasing interest and importance of PPPs in the parasite biology. The complements of phosphatases of the PPP and PPM families were analyzed in parasitic protozoa namely, apicomplexan parasite, Giardia lamblia, Entamoeba histolytica, Trichomonas vaginalis and Encephalitozoon cuniculi [110]. Pseudophosphatases with putative $\mathrm{Ca} 2+$ binding domains, referred as EFPP, were identified as unique PPPs in some apicomplexan parasites. The genome of Encephalitozoon cuniculi, a microsporidium parasite infecting rabbits causing partial or complete paralysis and kidney disease, was shown to have smallest set of protein phosphatases with only 5 PPPs and no PPM. While genome of Trichomonas vaginalis, the most common anaerobic parasitic flagellated protozoan and the causative agent of trichomoniasis, contained largest set of 169 predicted protein phosphatases [110].

\section{ACKNOWLEDGEMENTS}

The authors acknowledge the support of USDA-ARS. The NCNPR is partly supported by USDA-ARS under a scientific cooperative agreement.

\section{REFERENCES}

[1] Greenwood, B.M.; Fidock, D.A.; Kyle, D.E.; Kappe, S.H.; Alonso, P.L.; Collins, F.H. and Duffy, P.E. (2008) J. Clin. Invest., 118(4), 1266-1276.

[2] Ringwald, P. (2008) Bull. Acad. Natl. Med., 191(7), 1273-1284.

[3] Kooij, T.W.; Janse, C.J. and Waters, A.P. (2006) Nat. Rev. Microbiol., 4, 344-357.

[4] Zhou, Y.; Ramachandran, V.; Kumar, K,A.; Westenberger, S.; Refour, P.;Zhou, B.; Li, F.; Young, J.A.; Chen, K.; Plouffe, D.,
Henson, K.; Nussenzweig, V.; Carlton, J.; Vinetz, J.M.; Duraisingh, M.T. and Winzeler, E.A. (2008) PLoS ONE, 3(2), e1570.

[5] Joubert, Y. and Joubert, F. (2008) Malaria J., 7, 90.

[6] Sakata, T. and Winzeler, E.A, (2007) Mol. BioSyst, 3(12), 841-848.

[7] Bathurst, I. and Hentschel, C. (2007) Trends Parasitol., 22(7), 301307.

[8] Sopko, R. and Andrews, B.J. (2008) Mol. Biosyst., 4, 920-933.

[9] Cohen, P.T.W. (2002) J. Cell. Sci., 115(2), 241-256.

[10] Farkas, I.; Dombradi, V.; Miskei, M.; Szabados, L. and Koncz, C. (2007) Trends Plant Sci., 12(4), 169-176.

[11] Brenchley, R.; Tariq, H.; McElhinney, H.; Ször, B.; Huxley-Jones, J.; Robert Stevens, R.; Matthews, K. and Tabernero, L. (2007) B.M.C. Genetics, 8,434

[12] Hombauer, H.; Weismann, D.; Mudrak, I.; Stanzel, C.; Fellner, T.; Lackner, D. and Ogris, E. (2007) PLoS Biol., 5(6), 155.

[13] Cohen, P.T.W. (2004) in Topics in current genetics: protein phosphatases, (Arino, J. and Alexander, D.R., Ed.), Springer-Verlag, Berlin, Heidelberg, 5, pp. 1-20.

[14] Bork, P.; Brown, N.P.; Hegyi, H. and Schultz, J. (1996) Prot. Sci., $\mathbf{5}(7), 1421-1425$.

[15] Barford, D. (1996) TiBS, 21(11), 407-412

[16] Zolnierowicz, S. and Bollen, M. (2000) EMBO J., 19, 483-488.

[17] Ma, R.; Kanders, E.; Beckman Sundh, U.; Geng, M.; Ek, P.; Zetterqvist, O. and Li J.-P. (2005) Biochem. Biophys. Res. Commun., 337(3), 887-891

[18] Busam, R.D.; Thorsell, A.-G.; Flores, A.; Hammarstro"m, M. Persson, C. and Hallberg B.M. (2006) J. Biol. Chem., 281(45), 33830-33834.

[19] Zhang, Z.Y.; Zhou, B. and Xie, L. (2002) Pharmacol. Ther., 93, 307- 317.

[20] Bhattacharyya, M.K.; Hong, Z.; Kongkasuriyachai, D. and Kumar, N. (2002) Int. J. Parasitol., 32(6), 739-747.

[21] Dounay, A. and Forsyth C. (2002) Curr. Med. Chem., 9(22), 19391980.

[22] Dobson, S.; Bracchi, V.; Chakrabarti, D. and Barik, S. (2001) Mol. Biochem. Parasitol., 115(1), 29-39.

[23] McCluskey, A. and Sakoff, J.A. (2001) Mini Rev. Med. Chem., 1(1), 43-55.

[24] Gallego, M. and Virshup, D.M. (2005) Curr. Opin. Cell. Biol., 17(2), 197-202.

[25] Wakula, P.; Beullens, M.; Ceulemans, H.; Willy Stalmans, W. and Bollen, M. (2003) J. Biol. Chem., 278(21), 18817-18823.

[26] Ceulemans, H.; Vulsteke, V.; De Maeyer, M.; Tatchell, K.; Stalmans, W. and Bollen, M. (2002) J. Biol. Chem., 277(49), 4733147337.

[27] Ceulemans, H. and Bollen, M. (2004) Physiol. Rev., 84(1), 1-39.

[28] Brichese, L. and Valette, A. (2002) Biochem. Biophys. Res. Commun., 294(2), 504-508.

[29] Llorian, M.; Beullens, M.; Andrés, I.; Ortiz, J.M. and Bollen M. (2004) Biochem. J., 378(15), 229-238.

[30] Sim, A.T.R. and Ludowyke, R.L. (2002) IUBMB Life, 53(6), $283-$ 286.

[31] Ruediger, R.; Hentz, M.; Fait, J., Mumby, M., and Walter, G. (1994) J. Virol., 68(1), 123-129.

[32] Jassens, V.; Goris, J. and Van Hoof, C. (2001) Curr. Opin. Genet. Dev., 15, 34-41.

[33] Lechward, K.; Awotunde, O.S.; Swiatek, W. and Muszynska, G. (2001) Acta Biochim. Pol., 48(4), 921-933.

[34] Zhou, J.; Pham, H.T. and Walter, G. (2003) J. Biol. Chem., 278(10), 8617-8622.

[35] Sontag, E. (2001) Cell Signal, 13(1), 7-16.

[36] Yoo, S.J.-S.; Boylan, J.M.; Brautigan, D.L. and Gruppuso, P.A. (2007) Arch. Biochem. Biophys., 461(2), 186-193.

[37] Ikehara, T.; Ikehara, S.; Imamura, S.; Shinjo, F.; Yasumoto, T. (2007) Biochem. Biophys. Res. Commun., 354(4), 1052-1057.

[38] Goldberg, Y., (1999) Biochem. Pharmacol., 57(4), 321-328.

[39] Rodriguez-Viciana, P.; Collins, C. and Fried, M. (2006) Proc. Natl. Acad. Sci. USA, 103(51), 19290-19295.

[40] Pei, J.-J.; Gong, C.-X.; An, W.-L.; Winblad, B.; Cowburn, R.F.; Grundke-Iqbal, I. and Iqbal, K. (2003) Am. J. Pathol., 163(3), 845858. 
[41] Kumar, R.; Adams, B.; Oldenburg, A.; Musiyenko, A.; Barik, S. (2002) Malaria J., 1(5), 1-11.

[42] Li, J.-L. and Baker, D.A. (1998) Mol. Biochem. Parasitol., 95(2), 287-295.

[43] Dobson, S.; May, T.; Berriman, M.; Del Vecchio, C.; Fairlamb, A.H.; Chakrabarti, D.; Barik, S. (1999) Mol. Biochem. Parasitol., 99(2), 167-81.

[44] Li, J.-L. and Baker, D.A. (1997) Eur. J. Biochem., 249(1), 98-106.

[45] Dobson, S.; Kar, B.; Kumar, R.; Adams, B. and Barik, S. (2001) BMC Mol. Biol., 1, 31.

[46] Lindenthal, C. and Klinkert, M.-Q. (2002) Mol. Biochem. Parasitol., 120(2), 257-268.

[47] Kumar, R.; Musiyenko, A.; Oldenburg, A.; Adams, B. and Barik, S. (2004) B.M.C. Mol. Biol., 5(1), 6.

[48] Mamoun, C.B., Sullivan, D.J. Jr., Banerjee, R. and Goldberg, D.E. (1998) J. Biol. Chem., 273(18), 11241-11247.

[49] Andreeva, A.V. and Kutuzov M.A. (2004) BMC Evol. Biol., 4, 5.

[50] Hugo, H. and Bollen, M. (2004) Physiol. Rev., 84(1): 1-39.

[51] Yokoyama, D.; Saito-Ito, A.; Asao, N.; Tanabe, K.; Yamamoto, M. and Matsumura, T. (1998) Biochem. Bioph. Res. Commun., 247(1), 18-23.

[52] Blisnick, T.; Vincensini, L.; Fall, G.; Braun-Breton, C. (2006) Cell. Microbiol., 8(4), 591-601.

[53] Le Roch, K.G.; Zhou, Y.; Blair, P.L.; Grainger, M.; Moch, J.K.; Haynes, J.D.; De LaVega, P.; Holder, A.A.; Batalov, S.; Carucci D.J. and Winzeler, E.A. (2003) Science, 301(5639), 1503-1508.

[54] Kutuzov, M.A. and Andreeva, A.V. (2002) Cell Signal., 14(9), 745-750.

[55] Kumar, R.; Musiyenko, A. and Barik, S. (2005) Mol. Biochem. Parasitol., 141(2), 29-37.

[56] Swingle, M.R.; Honkanen, R.E. and Ciszak, E.M. (2004) J. Biol. Chem., 279(32), 33992-33999.

[57] Zuo, Z.; Dean, N.M. and Honkanen, R.E. (1998) J. Biol. Chem., 273(20), 12250-12258.

[58] Ryu, J.S.; Kim, J.-I.; Kunkel, T.; Kim, B.Ch.; Cho, D.S.; Hong, S.H.; Kim, S.-H.; Fernández, A.P.; Kim, Y.; Alonso, J.M.; Ecker, J.R.; Nagy, F.; Pyung Ok Lim, P.O.; Song, P.-S.; Schäfer, E. and Nam, H.G. (2005) Cell, 120(3), 395-406.

[59] Mamoun, C.B. and Goldberg, D.E (2001) Mol. Microbiol., 39, 973981.

[60] Egloff, M.-P.; Cohen, P.T.W.; Reinemer, P. and Barford D. (1995) J. Mol. Biol., 254(5), 942-959.

[61] Delwiche, C.F. and Palmer, J.D. (1997) Pl. Syst. Evol. [Suppl], 11, 51-86.

[62] Morden, C.W.; Delwiche, C.F.; Kuhsel, M. and Palmer, J.D. (1992) Biosystems, 28, 75-90.

[63] Llinas, M. and DeRisi, J. (2004) Curr. Opin. Microbiol., 7(4), 382387.

[64] Functional Genomics Workshop Group Summary of a Meeting Held September 15, 2006 (2007) Am. J. Trop. Med. Hyg., 77, 201208

[65] Daher, W.; Browaeys, E.; Pierrot, C.; Jouin, H.; Dive, D.; Meurice, E.; Dissous, C.; Capron, M.; Tomavo, S.; Doerig, C.; Cailliau, K. and Khalife, J. (2006) Mol. Microbiol., 60(3), 578-590.

[66] Yanagida, M.; Kinoshita, N.; Stone, E.M. and Yamano, H. (1992) Ciba. Found. Symp., 170, 130-140; discussion 140-146.

[67] Swain, J.E.; Wang, X.; Saunders, T.L.; Dunn, R. and Smith, G.D. (2003) Mol. Reprod. Dev., 65(1), 96-103.

[68] Dobson, S.; Kumar, R.; Bracchi-Ricard, V.; Freeman, S.; AlMurrani, S.W.K.; Corey, J.; Damuni, Z.; Chakrabarti, D. and Barik, S. (2003) Mol. Bioch. Parasitol., 126(2), 239-250.

[69] McCluskey, A.; Sim, A.T.R. and Sakoff, J.A. (2002) J. Med. Chem., 45(66), 1151-1174.

[70] Oliver, C.J. and Shenolikar S. (1998) Front. Biosci., 3, 961-972.

[71] Egloff, M. P.; Johnson, D. F.; Moorhead, G.; Cohen, P. T.; Cohen, P. and Barford, D. (1997) EMBO J., 16, 1876-1887.

[72] Van Eynde, A.; Wera, S.; Beullens, M.; Torrekens, S.; Van Leuven, F.; Stalmans, W. and Bollen, M. (1995) JBC, 270(47), 2806828074.

[73] Zhang, J.; Zhang, L.; Zhao, S. and Lee, E. Y. C. (1998) Biochemistry, 37, 16728-16734.
[74] Shirato, H.; Shima, H.; Sakashita, G.; Nakano, T.; Ito, M.; Lee, E.Y.C. and Kikuchi, K. (2000) Biochem., 39(45), 13848-13855.

[75] Wang, X.; Liu, B.; Li, N.; Li, H.; Qiu. J.; Zhang, Y. and Cao, X.; (2008) J. Biol. Chem.,18,12076-84.

[76] Tsujio, I.; Zaidi, T.; Xu, J.; Kotula, L.; Grundke-Iqbal, I. and Iqbal, K. (2005) FEBS Lett., 579(2), 363-372.

[77] Shirane, M. and Nakayama, K.I. (2003) Nat. Cell Biol., 5, 28-37.

[78] Kumar, R.; Adams, B.; Musiyenko, A.; Shulyayeva, O. and Barik, S. (2005) Mol. Biochem. Parasitol., 141(2), 163-173.

[79] Görlach, J.; Fox, D.S.; Cutler, N.S.; Cox, G.M.; Perfect, J.R. and Heitman, J. (2000) EMBO J., 19, 3618-3629.

[80] Hall, K.U.; Collins, S.P.; Gamm, D.M.; Enrique Massa, E.; DePaoli-Roach, A.A. and Uhler, M.D. (1999) JBC, 274(6), 3485-3495.

[81] Endo, S.; Suzuki, M.; Sumi, M.; Nairn A.C.; Morita R.; Yamakawa, K.; Greengard, P. and Ito, M. (1999) Proc. Natl. Acad. Sci. USA, 96(5), 2467-2472.

[82] Endo, S.; Nairn, A.C.; Greengard, P. and Ito, M. (2003) Neurosci. Res., 45(1), 79-89.

[83] Eto, M.; Senba, S.; Morita, F. and Yazawa, M. (1997) FEBS Lett., 410, 356-360.

[84] Beullens, M.; Stalmans, W. and Bollen M. (1996) Eur. J. Biochem., 239(1), 183-189.

[85] Fabian, L.; Troscianczuk, J. and Forer, A. (2007) Cell Chromosome, 6, 1-17.

[86] Li, Y.-M. and Casida J.E. (1992) Proc. Natl. Acad. Sci. USA, 89(24), 11867-11870.

[87] Hill, T.A.; Stewart, S.G.; Ackland, S.P.; Gilbert, J.; Sauer, B.; Sakoff J.A. and McCluskeya, A. (2007) Bioorgan. Med. Chem., 15(18), 6126-6134.

[88] MacKintosh, C.; Beattie K.A.; Klumpp, S.; Cohen, P. and Codd, G.A. (1990) FEBS Lett., 264(2), 187-192.

[89] Fujiki, H.; Suganuma, M.; Yoshizawa, S.; Nishiwaki, S.; Winyar, B. and Sugimura, T. (1991) Environ. Health. Perspect., 93, 211214.

[90] Kawamura, T.; Matsuzawa, S.; Mizuno, Y.; Kikuchi, K.; Oikawa, H.; Oikawa, M.; Ubukata, M. and Ichihara A. (1998) Biochem. Pharmacol., 55(7), 995-1003.

[91] Roberge, M.; Tudan, C.; Hung, S.M.F.; Harder, K.W.; Jirik, F.R and Anderson H. (1994) Cancer Res., 54(23), 6115-6121.

[92] Groblewski, G.E.; Wagner, A.C. and Williams, J.A. (1994) J. Biol. Chem., 269(21), 15111-15117.

[93] Jaumot, M. and Hancock, J.F. (2001) Oncogene, 20(30), 39493958.

[94] Enan, E. and Matsumura, F. (1992) Biochem. Pharmacol., 43(8), 1777-1784

[95] Sakoff, J.A.; Ackland, S.P.; Baldwin, M.L.; Keane, M.A. and McCluskey A. (2002) Invest. New Drug, 20, 1-11.

[96] Larsen, A.K; Escargueil, A.E. and Skladanowski, A. (2003) Pharmacol. Therapeut., 99, 167-181.

[97] Lê, L.H.; Erlichman, C.; Pillon, L.; Thiessen, J.J.; Day, A.; Wainman, N.; Eisenhauer, E.A. and Moore M.J. (2004) Invest. New Drug, 22(2):159-167

[98] David R.H. Evans, D.R.H. and Julian A. Simon, J.A. (2001) FEBS Lett., 498(1), 110-115.

[99] Baba, Y.; Hirukawaa, N. and Sodeokaa, M. (2005) Bioorgan. Med. Chem., 13, 5164-5170.

[100] Walsh, A.H.; Cheng, A. and Honkanen R.E. (1997) FEBS Lett., 416(3), 230-234.

[101] Nikbakhtzadeh, M.R.; Dettner, K.; Boland, W.; Gäde, G. and Dötterl S. (2007) J. Insect Physiol., 53(9), 890-899.

[102] Li, Y.-M.; Mackintosh, C. and Casida, J.E. (1993) Biochem. Pharmacol., 46(8), 1435-1443.

[103] McCluskey, A.; Ackland, S.P.; Bowyer, M.C.; Baldwin, M.L.; Garner, J.; Walkom, C.C. and Sakoff, J.A. (2003) Bioorg. Chem., 31(1), 68-79.

[104] Laidley, C.W.; Dauben, W.G.; Guo, Z.R.; Lam, J.Y.L. and Casida J.E. (1999) Bioorgan. Med. Chem., 7(12), 2937-2944.

[105] Efferth, T.; Rauh, R.; Kahl, S.; Tomicic, M.; Böchzelt, H.; Tome, M.E.; Briehl, M.M.; Bauer, R. and Kaina, B. (2005) Biochem. Pharmacol., 69(5), 811-818. 
[106] Bonness, K.; Aragon, I.V.; Rutland, B.; Ofori-Acquah, S.; Dean, N.M. and Honkanen, R.E. (2006) Mol. Cancer Ther., 5(11), 27272736.

[107] Hart, M.E.; Chamberlin, A.R.; Walkom, C.; Sakoff, J.A. and McCluskey, A. (2004) Bioorg. Med. Chem. Lett., 14, 1969-1973.

Received: August 11, 2008
[108] Bajsa, J.; Singh, K.; Nanayakkara, D.; Duke, S.O.; Rimando, A.M.; Evidente, A. and Tekwani, B.L. (2007) Biol. Pharm. Bull., 30(9), 1740-1744.

[109] Kutuzov, M.A. and Andreeva, A.V. (2008) Mol. Biochem. Parasitol., 161(2), 81-90.

[110] Tamura, K.; Dudley, J.; Nei, M. and Kumar, S. (2007) Mol. Biol. Evol., 24(8),1596-1599. 